Journal Of Natural Products

November 2014, Volume 77 Issue 11 Pages 2465-2474

http://dx.doi.org/10.1021/np500555k

\title{
Isolation, Structure Elucidation, Relative LC-MS Response, and in Vitro Toxicity of Azaspiracids from the Dinoflagellate Azadinium spinosum
}

\author{
Kilcoyne Jane ${ }^{1,2, *}$, Nulty Ciara ${ }^{1}$, Jauffrais Thierry ${ }^{3,4}$, Mccarron Pearse ${ }^{5}$, Herve Fabienne ${ }^{3}$, \\ Foley Barry ${ }^{2}$, Rise Frode ${ }^{6}$, Crain Sheila ${ }^{5}$, Wilkins Alistair $\mathrm{L}_{7,9}{ }^{7}$, Twiner Michael J. ${ }^{8}$, Hess Philipp ${ }^{3}$, \\ Miles Christopher O. ${ }^{7}$
}

${ }^{1}$ Inst Marine, Galway, Ireland.

2 Dublin Inst Technol, Sch Chem \& Pharmaceut Sci, Dublin 8, Ireland.

${ }^{3}$ IFREMER, Lab Phycotoxines, F-44311 Nantes, France.

${ }^{4}$ Univ Nantes, Fac Sci \& Tech, Mer Mol Sante EA2160, F-44322 Nantes, France.

${ }^{5}$ Natl Res Council Canada, Halifax, NS B3H 3Z1, Canada.

${ }^{6}$ Univ Oslo, Dept Chem, N-0315 Oslo, Norway.

${ }^{7}$ Norwegian Vet Inst, N-0106 Oslo, Norway.

${ }^{8}$ Univ Michigan, Dept Nat Sci, Dearborn, MI 48128 USA.

${ }^{9}$ Univ Oslo, Sch Pharm, Dept Pharmaceut Chem, N-0316 Oslo, Norway.

Corresponding author : Jane Kilcoyne, email address : jane.kilcoyne@marine.ie

\begin{abstract}
:
We identified three new azaspiracids (AZAs) with molecular weights of 715,815 , and 829 (AZA33 (3), AZA34 (4), and AZA35, respectively) in mussels, seawater, and Azadinium spinosum culture. Approximately $700 \mathrm{mu} g$ of 3 and $250 \mathrm{mu} \mathrm{g}$ of 4 were isolated from a bulk culture of $A$. spinosum, and their structures determined by MS and NMR spectroscopy. These compounds differ significantly at the carboxyl end of the molecule from known AZA analogues and therefore provide valuable information on structure-activity relationships. Initial toxicological assessment was performed using an in vitro model system based on Jurkat T lymphocyte cytotoxicity, and the potencies of 3 and 4 were found to be 0.22 and 5.5-fold that of AZA1 (1), respectively. Thus, major changes in the carboxyl end of 1 resulted in significant changes in toxicity. In mussel extracts, 3 was detected at low levels, whereas 4 and AZA35 were detected only at extremely low levels or not at all. The structures of 3 and 4 are consistent with AZAs being biosynthetically assembled from the amino end.
\end{abstract}


<smiles>C[C@H]1C[C@H]2O[C@H]([13CH3])C[C@H]2O[C@]12CC[C@]1(CC=C[C@@H](/C=C/CCC(=O)O)O1)O2</smiles>

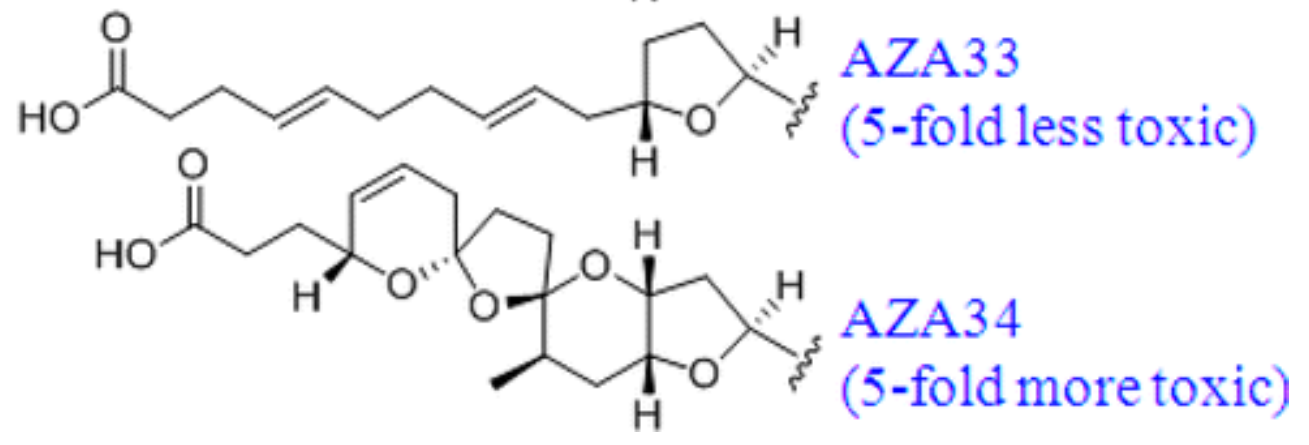


Numerous azaspiracid (AZA) analogues have been identified in shellfish, ${ }^{1,2}$ however, only AZA1 (1), AZA2 (2) and AZA3 are currently regulated by the European Union. ${ }^{3}$ Compounds 1 and 2 are produced by the dinoflagellate Azadinium spinosum, ${ }^{4}$ while the majority of the other reported analogues are due to shellfish metabolism. ${ }^{5-7}$

A number of toxicological studies have shown AZAs to be teratogenic in fish, ${ }^{8}$ damaging to the gastrointestinal tract in mice,,${ }^{9,10}$ and potential lung tumour promoters. ${ }^{11} \mathrm{~A}$ recent in vitro study on 1, 2 and AZA3 confirmed the high potency of AZAs and suggested multiple molecular targets for these compounds which are differentially affected by the various AZA analogues. ${ }^{12,13}$ However, further toxicological studies need to be performed on as many AZA analogues as possible to establish more accurate regulatory limits and to identify all analogues that are relevant for public health protection.

The isolation and structure elucidation of 1, 2, AZA3-6 ${ }^{14-17}$ and $37-e p i-A Z A 1^{18}$ from shellfish have been reported. Purification of these compounds is necessary: 1) to enable the preparation of certified reference materials (CRMs), which are essential for the successful implementation of monitoring programs; 2) for use in toxicology studies, so that regulators can implement appropriate closure limits, and; 3 ) for structure elucidation by NMR, enabling a better understanding of the chemistry involved. Isolation of AZAs from shellfish is a labour intensive procedure requiring up to eight steps involving extraction, partitioning and column chromatography. ${ }^{17,19}$ Such compounds are ideally isolated from cultures of the producing organisms due to the initial extract being significantly cleaner than from shellfish, and therefore requiring fewer purification steps. ${ }^{20-22}$ Isolation of AZAs from a marine sponge ${ }^{23}$ and cultures of $A$. spinosum ${ }^{24}$ have been reported.

More recently, the presence of unidentified AZAs in the dinoflagellates Amphidoma languida (with molecular weights of 815 and $829 \mathrm{Da}$ ) and Azadinium poporum (with molecular weights of 845 and $857 \mathrm{Da}$ ) were reported. ${ }^{25}$ All of the AZAs identified previously give a characteristic LC-MS/MS fragment at $\mathrm{m} / \mathrm{z} 362$, whereas these compounds gave an $\mathrm{m} / \mathrm{z} 348$ fragment, suggesting the lack of a methyl or methylene group in rings $E-I$ (Figure 1). AZAs were also detected in isolates of $A$. poporum from Chinese coastal waters. ${ }^{26}$ Although one strain did not produce detectable AZAs, three other strains produced exclusively $2{ }^{26}$ Furthermore, AZAs (with molecular weights of 827,857 and $829 \mathrm{Da}$ ) were present in a newly discovered strain Azadinium dexteroporum, all of which produced the characteristic $\mathrm{m} / \mathrm{z} 362$ LC-MS/MS fragments. ${ }^{27}$

Here we report the identification of three new AZAs - AZA33 (3), AZA34 (4) and AZA35 from a bulk culture of $A$. spinosum, two of which were isolated in sufficient quantities for structure elucidation by NMR spectroscopy. We additionally report on their stability, toxicity and relative response factors in LC-MS/MS analysis, and assess their relevance in terms of human health protection. 
In 2009, preliminary analysis (data not shown) of SPATT (Solid Phase Adsorption Toxin Tracking) disks deployed at Bruckless, Ireland, in $2005^{28}$ during a major AZA event (where levels in mussels reached $\sim 9 \mu \mathrm{g} / \mathrm{g}$ AZA equivalents ${ }^{29}$ ), showed the presence of numerous candidate AZAs, including new analogues with $\mathrm{m} / \mathrm{z} 716.4745,816.4909$, and 830.5069. Subsequent analysis of extracts from a culture of $A$. spinosum by LC-MS/MS showed the presence of three new AZAs showing accurate masses of $m / z 716.4759$ (3), 816.4900 (4) and 830.5046 (AZA35). Compound 3 was also subsequently detected in an $A$. spinosum (SHETF6) extract collected from the Shetland Islands by Tillmann et al. ${ }^{30}$ The three compounds all had fragmentations characteristic of AZAs (Figure 2). The ratios of 2 and $\mathbf{3}$, relative to 1 were both 0.3 in cells of $A$. spinosum cultures (SM2 and 3D9 strains). Compounds 4 and AZA35 were much less abundant with ratios of 0.15 , and 0.02 relative to $\mathbf{1}$, respectively, found in the culture medium of the 3D9 strain (Figure 3).

Analysis of shellfish samples contaminated with 1, 2 and AZA3 (0.08-8.0 $\mu \mathrm{g} / \mathrm{g}$ AZA equivalents), tested as part of the routine biotoxin monitoring programme at the Marine Institute, were also analysed for 3, 4 and AZA35. Compound $\mathbf{3}$ was detected in all samples tested, 4 was only detected $(<0.04 \mu \mathrm{g} / \mathrm{g})$ in samples with $>4.0 \mu \mathrm{g} / \mathrm{g}$ AZA equivalents, while AZA35 was not detected in any of the samples. The levels of $\mathbf{3}$, relative to $\mathbf{1}$ and $\mathbf{2}$, in the SPATTs and shellfish were significantly lower than in the cultures (SM2 and 3D9 strains) (Figure 3), suggesting that 3 might be chemically transformed in seawater and shellfish.

After tangential flow filtration of a bulk culture of $A$. spinosum into retentate and permeate,$^{24} 4$ and AZA35 were detected only in the permeate (Figures 3 and 4). Similarly, higher levels of 4 were detected in the SPATT extracts relative to the $A$. spinosum culture extracts suggesting that these compounds may be extracellular, perhaps being produced within the cell and excreted. Alternatively, they may simply be released after cellular lysis or mechanical stress on the cellular membranes during pumping and filtration. In any case, shellfish have been shown to be capable of absorbing AZAs from the both algal cells and the dissolved phase. ${ }^{31}$

Epimers of 1, 2, AZA3 and AZA6 at C-37 have previously been reported using LC-MS with a neutral eluent. ${ }^{18,32}$ LC-MS analysis of $A$. spinosum extracts and purified samples of 3 and $\mathbf{4}$ using a neutral eluent showed the presence of additional peaks (ranging from $\sim 5-12 \%$ relative to the parent peak) which were not observed using an acidic eluent. The spectra of these peaks differed from those of the parent compounds only in their fragment ion ratios, as was observed for 37 -epi-AZA1. ${ }^{18}$ It is likely that these peaks correspond to the 37 -epimers of $\mathbf{3}$ and $\mathbf{4}$ (Supporting Information).

Compounds $3(700 \mu \mathrm{g})$ and $4(150 \mu \mathrm{g})$ were isolated from the culture extract of $A$. spinosum (3D9) used for the isolation of $\mathbf{1}$ and 2 that has been described previously. ${ }^{24}$ The stabilities of 3 and 4 were compared with that of 1 over a period of 7 days at $-18^{\circ} \mathrm{C},+20$ ${ }^{\circ} \mathrm{C}$ and $+40{ }^{\circ} \mathrm{C}$ in $\mathrm{MeOH}$. Both compounds exhibited similar stability to 1; each being stable at the freezer and room temperatures over 7 days with minor degradation (<5\%) after 7 days of storage at $40^{\circ} \mathrm{C}$ (Supporting Information).

\section{Structure Determination.}

High Resolution MS data were consistent with 3,4 and AZA35 possessing the molecular formulae shown in Table 1, indicating that 3, 4 and AZA35 possess six, two, and one fewer carbon atoms than $\mathbf{1}$, respectively.

The mass spectrum of 3 (Figure 2) showed typical AZA-type $\mathrm{H}_{2} \mathrm{O}$ loss fragments $(\mathrm{m} / \mathrm{z} 698$ and 680). Additionally, fragments at $\mathrm{m} / \mathrm{z} 362$ and 462 suggested that the amino end (i.e., C- 
21-C-40 and substituents) of 1 was also present in 3. No retro Diels-Alder (RDA) fragment was present, however, suggesting that the $A / B / C$ ring-system of 3 differed from that of 1 . Thus, the carboxyl end of 3 (i.e., C-1-C-19) differed from that of 1 by the absence of $\mathrm{C}_{6} \mathrm{H}_{6} \mathrm{O}_{3}$ and by the presence of four instead of seven rings/double bonds.

Compound 4 also displayed $\mathrm{H}_{2} \mathrm{O}$ loss fragments $(\mathrm{m} / \mathrm{z} 798$ and 780$)$, but also showed an RDA fragment at $\mathrm{m} / \mathrm{z} 672$, in addition to fragments at $\mathrm{m} / \mathrm{z} 362$ and 462 that are characteristic of the C-21-C-40 moiety of 1 (Figure 2). The MS data therefore suggested that the structure of $\mathbf{4}$ was very similar to that of $\mathbf{1}$, including an intact A-ring, and that $\mathbf{4}$ differed from $\mathbf{1}$ by loss of $\mathrm{C}_{2} \mathrm{H}_{4}$ from the side chain attached to the A-ring.

The mass spectrometric data for AZA35 (Figure 2 and Table 1) are consistent with an additional $\mathrm{CH}_{2}$ group in the structure of 4 between $\mathrm{C}-3$ and $\mathrm{C}-9$, possibly in the form of a methyl group at C-8 (as in 2). NMR data will be required to confirm this proposal.

LC-MS analysis showed that treatment of 3 and $\mathbf{4}$ with periodate yielded the same C-20-C21 -cleavage product $(\mathrm{m} / \mathrm{z} 448)$ as was obtained by treatment of 1 . This establishes not only the presence of a 20,21-diol in both 3 and 4, but confirms that the same C-21-C-40 moiety that is present in $\mathbf{1}$ is also present in $\mathbf{3}$ and $\mathbf{4}$.

Purified 3 and 4 were treated with diazomethane. LC-MS/MS analysis confirmed conversion to the corresponding methyl esters, thus establishing the presence of a carboxyl group in the side-chain attached at C-16 or C-6, respectively, of $\mathbf{3}$ and $\mathbf{4}$.

Detailed analysis of ${ }^{1} \mathrm{H},{ }^{13} \mathrm{C}$, DEPT135, COSY, TOCSY, SELTOCSY, HSQC and HMBC spectra of 3 showed the presence of the pentacyclic C-20-C-40 ring system, present in all other known AZAs, consistent with results of the periodate cleavage experiment. During NMR analysis of both 3 and 4 , a series of minor peaks ( 3-10\%) were also observed which were attributable to the corresponding 37-epimers, due to susceptibility of AZAs to epimerization in $\mathrm{MeOH}$ under neutral and weakly acidic conditions. ${ }^{18}$ The presence of these epimers is noted, but is not discussed further as these minor peaks did not interfere with NMR analysis of the parent compounds.

AZAs are characterized by a distinctive doublet-of-triplet-like signal, akin to a quartet, at 4.41-4.43 ppm ( $\mathrm{H}-19)$. The corresponding signal of 3 appeared at $4.08 \mathrm{ppm}(\mathrm{dt}, J=8.2,6.7$ $\mathrm{Hz}$ ). This indicated modification in $\mathbf{3}$ of the normal AZA structure in the vicinity of C-19, with the retention of three adjacent coupled protons $(\mathrm{H}-18$ and $\mathrm{H}-20)$. Correlations in the COSY spectrum confirmed that the $\mathrm{H}-19$ signal $(4.08 \mathrm{ppm})$ was coupled to $\mathrm{H}-20(3.34 \mathrm{ppm})$ and a pair of methylene proton signals $(\mathrm{H}-18 \mathrm{a} / \mathrm{b})$ at 1.95 and $2.00 \mathrm{ppm}$. In the TOCSY spectrum, $\mathrm{H}-$ 19 showed additional correlations to a pair of methylene protons centered at 1.92 and 1.55 ppm $(\mathrm{H}-17)$, and an oxygenated methine signal at $3.907 \mathrm{ppm}(\mathrm{H}-16)$, the chemical shift of which differed marginally from that of the $\mathrm{H}-25$ (3.911 ppm). In the HSQC spectrum, the foregoing protons showed correlations to carbons at 30.5 (C-18), 30.9 (C-17) and $81.5 \mathrm{ppm}$ (C-16). These observations are consistent with the attachment to C-20 (77.4 ppm), via C-19 $(80.3 \mathrm{ppm})$, of a tetrahydrofuran ring (two methylene carbons at 30.5 (C-18) and $30.9 \mathrm{ppm}$ (C-17) and an oxygenated methine carbon at $81.5 \mathrm{ppm}(\mathrm{C}-16))$, as in all other known AZAs. ${ }^{33}$ The structure of this tetrahydrofuran ring differs, however, from known AZAs in that it possesses two methylene carbons, indicating that it is not cis-fused to a six-membered pyran ring as is the case for all other AZAs. It follows that the remaining $\mathrm{C}_{10} \mathrm{H}_{15} \mathrm{O}_{2}$ portion of $\mathbf{3}$ (not accounted for by the proposed $\mathrm{C}-16$ to $\mathrm{C}-40$ substructure $\left.\left(\mathrm{C}_{31} \mathrm{H}_{50} \mathrm{NO}_{7}\right)\right)$ must be attached to the oxygenated $\mathrm{C}-16$ atom at $81.5 \mathrm{ppm}$. Moreover, it follows from the $\mathrm{C}_{10} \mathrm{H}_{15} \mathrm{O}_{2}$ formulation, that the residue attached to C-16 must possess a total of three rings and/or double bonds. The presence in this residue of a carboxyl group (also consistent with the diazomethane reactivity), two olefinic double bonds, and five methylene carbons was indicated by the occurrence of signals at $181.9 \mathrm{ppm}(\mathrm{COOH}), 127.8,130.8,131.5$ and $133.4 \mathrm{ppm}(2 \times$ 
$\mathrm{CH}=\mathrm{CH}$ groups), and at $30.9,33.9,34.1,39.7$ and $40.5 \mathrm{ppm}\left(5 \times \mathrm{CH}_{2}\right.$ groups), precluding the presence of rings in C-6-C-15.

Notwithstanding the appreciable overlap of the four olefinic proton signals (5.40-5.53 ppm, Figure $5 \mathrm{C}$ ), the resolution of the COSY spectrum was such that the connectivities depicted in Figure 1 could be established, and were supported by TOCSY and SELTOCSY spectra run with a range of mixing times. The resonances of the ${ }^{13} \mathrm{C}$ atoms to which these protons were attached were established by correlations observed in the HSQC spectrum.

$\mathrm{H}-16$ (3.907 ppm) showed COSY correlations to the $\mathrm{H}-17$ methylene protons (1.55 and 1.92 $\mathrm{ppm})$ and to the pair of diastereotopic side chain protons at 2.17 and $2.24 \mathrm{ppm}(\mathrm{H}-15)$. These protons show a COSY correlation to the least shifted of the four olefinic protons at $5.43 \mathrm{ppm}$ $(\mathrm{H}-14)$. In the HSQC spectrum, this proton exhibited a correlation to the olefinic carbon signal at $127.8 \mathrm{ppm}(\mathrm{C}-14)$. In the HMBC spectrum, $\mathrm{H}-16$ (3.907 ppm) showed a correlation to the olefinic C-14 carbon (127.8 ppm), and the protons at $5.43(\mathrm{H}-14)$ and $2.17(\mathrm{H}-15)$ also showed correlations to $133.4 \mathrm{ppm}$ (C-13). C-13 in turn showed an HSQC correlation to a methine signal at $5.50 \mathrm{ppm}(\mathrm{H}-13)$. These observations defined the location of the first of the two double bonds in the 10-carbon side chain attached to C-16.

The two pairs of methylene protons at $2.03 \mathrm{ppm}(4 \mathrm{H}$, br s, $\mathrm{H}-11$ and $\mathrm{H}-12)$ were not overlapped in the ${ }^{1} \mathrm{H}$ NMR spectrum by other signals, and showed COSY correlations only to the olefinic proton signals centered at $5.45(\mathrm{H}-10)$ and $5.50 \mathrm{ppm}(\mathrm{H}-13)$. In the HMBC spectrum, the protons at $2.04 \mathrm{ppm}$ showed correlations to the four olefinic carbons $(127.8$, $130.8,131.5$ and $133.4 \mathrm{ppm}$ ) and adjacent partner methylene carbons (33.9 and $34.1 \mathrm{ppm}$, $\mathrm{C}-11$ and $\mathrm{C}-12$ ). The resolution of the processed HMBC spectrum was such that while the four olefinic carbon correlations were resolved, the methylene carbon resonances, which differed by $0.2 \mathrm{ppm}$, were not. The foregoing COSY and HMBC observations demonstrated that the methylene carbons $(\mathrm{C}-11$ and $\mathrm{C}-12)$ with superimposed proton signals at $2.03 \mathrm{ppm}$ must be located between the C-9(10) and C-13(14) double bonds.

The remaining pair of methylene carbons at 30.9 and $39.7 \mathrm{ppm}$, which showed HSQC correlations to pairs of protons at $2.26(2 \mathrm{H})$ and $2.18(2 \mathrm{H}) \mathrm{ppm}$, respectively, and a terminal carboxyl group (181.9 ppm), must be attached to C-9. Consistent with this, the olefinic proton signal at $5.48(\mathrm{H}-9)$ ppm showed a COSY correlation to $2.26 \mathrm{ppm}(\mathrm{H}-8 \mathrm{a} / \mathrm{b})$, while HMBC correlations were observed between the proton signal at $2.18 \mathrm{ppm}(\mathrm{H}-7 \mathrm{a} / \mathrm{b})$ and the carboxyl carbon (C-6, $181.9 \mathrm{ppm})$ and a methylene carbon (C-8, $30.9 \mathrm{ppm})$.

Homonuclear decoupling experiments were also consistent with the attachment to C-16 of a 10 carbon side-chain (Figure 1). In particular, homonuclear decoupling at $2.04 \mathrm{ppm}$ under standard conditions collapsed the lines attributable to the $\mathrm{H}-10$ and $\mathrm{H}-13$ olefinic protons (5.45 ppm and $5.50 \mathrm{ppm}$, respectively) to $15.3 \mathrm{~Hz}$ doublets (Figure 5B). These couplings demonstrate that the 9(10)- and 13(14)-double bonds are both trans-substituted. Similarly, homonuclear decoupling at $2.21 \mathrm{ppm}$ (between the frequencies of the $\mathrm{H}-7$ and $\mathrm{H}-8$ methylene protons) using a higher power level that was also effective at decoupling the nearby $\mathrm{H}-15$ methylene protons (at 2.17 and $2.24 \mathrm{ppm})$, resulted in the $\mathrm{H}-9(5.48 \mathrm{ppm})$ and $\mathrm{H}-14(5.43 \mathrm{ppm})$ olefinic protons appearing as well-defined $15.3 \mathrm{~Hz}$ doublets (Figure $5 \mathrm{~A}$ ). Under these conditions, the $\mathrm{H}-10(5.45 \mathrm{ppm})$ and $\mathrm{H}-13(5.50 \mathrm{ppm})$ olefinic protons appeared as doublets $(J=15.3 \mathrm{~Hz})$ of poorly resolved, residually coupled, triplets $\left(J_{\text {residual }} \sim 1-2 \mathrm{~Hz}\right)$ due to incomplete decoupling of the adjacent $\mathrm{H}-11$ and $\mathrm{H}-12$ methylene protons at $2.04 \mathrm{ppm}$.

The $\mathrm{H}-19$ (4.08 ppm) proton of 3 exhibited ROESY correlations that paralleled those which we have previously observed for $1,{ }^{18}$ including moderate intensity inter-ring correlations to the equatorial $\mathrm{H}-40$ proton $(2.46 \mathrm{ppm})$ and the more shifted of the two olefinic 26-methylene protons $\left(\mathrm{H}-26_{z}, 5.27 \mathrm{ppm}\right)$. $\mathrm{H}-19(4.08 \mathrm{pm})$ also showed ROESY correlations to $\mathrm{H}-22$ (2.37 ppm) and the 22-methyl group (0.89 ppm), as did H-20 (3.34 ppm). H-16 (3.907 ppm) showed ROESY correlations to the adjacent $\mathrm{H}-15$ methylene protons ( 2.17 and $2.24 \mathrm{ppm})$ of 
the 10-carbon side-chain, and to one of the $\mathrm{H}-17$ protons (1.92 ppm), together with a low intensity $(0.15 \%)$ ROESY correlation to the more distant $\mathrm{H}-19$ proton $(4.08 \mathrm{ppm})$ as also seen in ROESY spectra of 1 and 2 . These observations showed that the C-16, C-19 and C20 configurations of $\mathbf{1}$ and $\mathbf{3}$ are essentially identical, that the dispositions of their $\mathrm{C}-16-\mathrm{C}-20$ tetrahydrofuran ring and $20-\mathrm{CHOH}$ groups are similar, and that the inter-ring spatial relationships between the C-19, C-26 and C-40 regions of 3 are comparable to those of 1 . These observations are consistent with the relative configuration proposed for the C-16-C-19 region of 3 (Figure 1).

In full accord with the mass spectrometric and periodate cleavage results discussed above, detailed analysis of ${ }^{1} \mathrm{H},{ }^{13} \mathrm{C}$, DEPT135, COSY, TOCSY, SELTOCSY, HSQC and HMBC spectra showed that 4 possessed an intact C-6-C-40 ring system and that the 5-carbon ringA-side-chain present at C-6 in all other reported AZAs had been replaced by a 3-carbon $\mathrm{CH}_{2}-\mathrm{CH}_{2}-\mathrm{COOH}$ side chain. The ${ }^{1} \mathrm{H}$ chemical shifts of the modified side chain methylene groups were elucidated via correlations in COSY and TOCSY spectra. H-6 (4.41 ppm), which was coincident with the $\mathrm{H}-19$ signal, exhibited COSY correlations to the $\mathrm{H}-5 \mathrm{a} / \mathrm{b}$ methylene protons (1.76 and $1.85 \mathrm{ppm})$. These correlations were readily differentiated from those which $\mathrm{H}-19$ exhibited to $\mathrm{H}-18 \mathrm{a} / \mathrm{b}$ (2.02 ppm), $\mathrm{H}-20$ (3.55 ppm), and $\mathrm{H}-17$ (4.19 ppm). The TOCSY spectrum at the frequency of $\mathrm{H}-6(4.41 \mathrm{ppm})$ and at the frequencies of other protons associated with the mutually coupled $\mathrm{H}-4 \mathrm{a} / \mathrm{b}-\mathrm{H}-5 \mathrm{a} / \mathrm{b}-\mathrm{H}-6-\mathrm{H}-7-\mathrm{H}-8-\mathrm{H}-9 \mathrm{a} / \mathrm{b}$ spin systems included correlations to 2.21 and $2.31 \mathrm{ppm}$, attributable to the $\mathrm{H}-4 \mathrm{a} / \mathrm{b}$ protons. The $\mathrm{H}-4$ and $\mathrm{H}-5$ methylene protons showed HSQC correlations to resonances at 34.7 and $33.2 \mathrm{ppm}(\mathrm{C}-4$ and $\mathrm{C}-5$, respectively), while the protons at 2.21 and $2.31(\mathrm{H}-4 \mathrm{a} / \mathrm{b})$ showed $\mathrm{HMBC}$ correlations to 181.9 (C-3), 70.5 (C-6) and 33.2 ppm (C-5).

The chemical shifts of carbons and protons associated with the C-6-C-40 portion of 4 were similar, but not in all cases identical, to those of $\mathbf{1}$ (Table 2) and several other AZAs. ${ }^{14-17}$ It is apparent from an analysis of published NMR data that the chemical shifts of atoms in the vicinity of the $40-\mathrm{NH}$ group and the C-20 portions of AZA are dependent on the $\mathrm{pH}$ of the examined NMR solutions. ${ }^{17,18}$ The presence of acetic acid (or deuteroacetic acid) in NMR solutions significantly increases the chemical shifts of the 40-methylene protons (reported chemical shifts for these protons are in the range $2.5-2.9 \mathrm{ppm}$ ), presumably due to protonation of the $\mathrm{NH}$ group, and that this in turn influences the chemical shifts of some of the other more remote protons (most notably $\mathrm{H}-20$; reported chemical shifts are in the range 3.5-3.9 ppm) that are in close proximity to $\mathrm{H}-19 .{ }^{18}$ However, because addition of weak acid promotes epimerization at $\mathrm{C}-37$, addition of $\mathrm{d}_{5}$-pyridine may be a better option for $\mathrm{pH}$ control during NMR analysis of AZAs. ${ }^{18}$

The NMR spectra of all AZAs examined in our laboratory, ${ }^{18}$ including $\mathbf{3}$ and $\mathbf{4}$, have exhibited moderate intensity inter-ring ROESY correlations between the equatorial $\mathrm{H}-40$ methylene proton and both $\mathrm{H}-19$ and the more shifted of the two protons of the exomethylene group located at C-26. Compound 4, in both 2D-ROESY and a series of 1D-SELROESY NMR experiments, exhibited an equivalent series of ROESY correlations to that observed for $\mathbf{1}$, including a moderate intensity ROESY correlation between $\mathrm{H}-6$ (4.41 ppm) and the 14methyl group $(0.95 \mathrm{ppm})$ which showed its C-6 configuration to be identical to that of 1 . H-6 (4.41 ppm) also showed ROESY correlations to the $\mathrm{H}-5 \mathrm{a} / \mathrm{b}$ protons (1.76 and $1.85 \mathrm{ppm}$ ). The foregoing ROESY correlations were readily distinguishable from those which the superimposed $\mathrm{H}-19$ signal showed to $\mathrm{H}-20$ (3.55 ppm), $\mathrm{H}-18 \mathrm{a} / \mathrm{b}$ (2.02 ppm), H-22 (2.24 $\mathrm{ppm})$, the 22-methyl group $(0.89 \mathrm{ppm})$ and one of the olefinic methylene protons attached to C-26 (5.26 ppm), because none of the correlations exhibited by the $\mathrm{H}-6$ and $\mathrm{H}-19$ signals overlapped and no nearby atoms possessed similar chemical shifts.

The NMR data provided definitive proof of the structures, showing that 3 consists of a trans,trans-4,8-decadienoic acid unit attached via its C-10 (i.e., C-15 of 3) to the C-16 of an AZA tetrahydrofuran D-ring. Compound 4 differed from 1 only by having a shorter three carbon side chain without the double bond. 
Many polyether toxins from dinoflagellates, such as okadaic acid and yessotoxin, are generated by cyclisation of a long carbon chain assembled primarily from acetate units via polyketide synthase enzyme clusters. ${ }^{34}$ Examination of their structures suggest that this is also likely for AZAs, with the polyether structure of 1 being assembled from a 40-carbon chain. If this is indeed the case, it would appear that $\mathbf{4}$ is assembled from a 38-carbon chain and $\mathbf{3}$ from a 35-carbon chain. The production of $\mathbf{4}$ is consistent with a failure to incorporate one acetate unit, into the growing carbon chain during polyether biosynthesis. The fact that 3 has an odd numbered chain length may be due to oxidative cleavage of a C-5/C- 6 double bond in a 40 carbon chain precursor. Furthermore, the structures of $\mathbf{3}$ and $\mathbf{4}$ suggest that AZAs may be assembled and cyclized from the amino-end, because in both of these compounds the C-19-C-40 substructure, including the relative configuration and all substituents, has been successfully assembled in an identical manner to 1 and 2 in $A$. spinosum's AZA-synthase.

\section{Relative Molar Response.}

Compounds 3 and 4 were quantitated by quantitative NMR (qNMR), and their molar responses in various LC-MS methods were assessed against purified $\mathbf{1}$, that had also been quantitated by qNMR. A number of LC-MS analyses were performed employing an acidic (isocratic and gradient) mobile phase in both SIM (selected ion monitoring) and SRM (selected reaction monitoring) modes.

LC-MS data obtained in SIM mode suggested that $\mathbf{3}$ and $\mathbf{4}$ had very similar responses to $\mathbf{1}$ when analysed under the various conditions (Table 3). In SRM mode, differences in response factors were observed. The response using the $\mathrm{H}_{2} \mathrm{O}$ loss fragment for 3 was similar to that for $\mathbf{1}$, while a higher response factor was obtained for $\mathbf{4}$. The RDA fragment for $\mathbf{4}$ gave a lower response factor than for $\mathbf{1}$, as did the $\mathrm{m} / \mathrm{z} 462$ fragment for 3 . The $\mathrm{m} / \mathrm{z} 362$ transitions for both 3 and 4 were slightly lower than that for 1 (Table 3). These results suggest that, in the absence of standards, 3 and 4 would be more accurately quantitated against $\mathbf{1}$ in SIM mode.

\section{Toxicity.}

Compounds $\mathbf{3}$ and $\mathbf{4}$ were cytotoxic to Jurkat T lymphocyte cells in a time- and concentrationdependent manner (Figure 6), and were 0.22 - and 5.5-fold as potent as 1, respectively (Table 4). Although these compounds were present in minor amounts relative to 1 and $\mathbf{2}$ in French and Irish shellfish, their major significance lies in their structural differences and their usefulness in establishing structure-activity relationships. Analogue 3 is similar to 1 but without the $A / B / C$ ring structure, while 4 differs from 1 only by the shorter side chain and absence of the 4,5- alkene. In the absence of the A/B/C ring structure, relative cytotoxic potency was reduced $\sim 5$-fold (relative to 1 ) (Table 4 ), suggesting that although this fragment of the AZA molecule influences toxicity, it is not the primary toxicophore or epitope necessary for AZAs to bind to and affect their target(s). On the other hand, the shorter side chain and absence of the 4,5-alkene in 4 enhanced cytotoxic potency by $>5$ fold (Table 4). This increase in potency may be due to greater interaction of the molecular target(s) with the negatively charged carboxylic acid due to the altered configuration. Although 1, 2 and AZA3 have been shown to induce apoptosis ${ }^{13}$ and selectively inhibit hERG potassium channels, ${ }^{35}$ the effects of $\mathbf{3}$ and $\mathbf{4}$ on these pathways have not yet been characterized. The results presented here suggest that it may be possible to link a reporter molecule in the vicinity of the carboxyl moiety of AZAs and still retain sufficient binding affinity to probe the AZAs' molecular target. 


\section{Conclusions}

Three new AZAs were identified in seawater (SPATT) samples and in cultured $A$. spinosum, two of which (3 and 4 ) were present in sufficient amounts for purification. Structures were determined by LC-MS/MS and NMR spectroscopy. Compound 3 was found to have major structural differences compared to $\mathbf{1}$, while 4 only differed by a shorter side chain and the lack of an alkene group at the C-4-C-5 position. The fact that 4 was more abundant in natural seawater samples and in culture medium raises questions regards its biological and ecological roles. Analysis of these AZAs using a neutral mobile phase indicates that 37epimers also exist for these compounds.

Cytotoxicity was assessed employing Jurkat T lymphocyte cells, and potencies relative to 1 for 3 and $\mathbf{4}$ were found to be 0.22 and 5.5, respectively. Both $\mathbf{3}$ and $\mathbf{4}$ were present in Irish mussels at very low levels and are not considered of relevance to human health. However, with the notable differences in structure and potency, these analogues further our knowledge of AZA structure-activity relationships.

\section{Experimental section}

\section{General Experimental Procedures.}

NMR experiments for structure elucidation were run using Bruker Avance I and Avance II $600 \mathrm{MHz}$ spectrometers equipped with $\mathrm{TCl}$ cryoprobes and Z-gradient coils, at $30{ }^{\circ} \mathrm{C}$ and a Bruker DRX-500 spectrometer was used for qNMR.

Mass spectrometric studies were performed using a Waters 2695 LC coupled to a Micromass triple-stage quadrupole (TSQ) Ultima, a Waters 2795 LC coupled to a Micromass quadrapole time of flight (QToF) Ultima and an Agilent 1200 LC system connected to an API4000 QTRAP mass spectrometer equipped with a Turbospray ionization source.

\section{Biological Material.}

A. spinosum strains were collected from the West coast of Ireland $\left(\mathrm{SM}^{6}\right)$ and the North Sea $\left(3 \mathrm{D} 9^{36}\right)$. Mytilus edulis samples contaminated with AZAs were obtained from shellfish harvesting sites along the West coast of Ireland. SPATT extracts generated in studies carried out by Fux et al. ${ }^{28,37}$ were used for analysis. The SPATTs were deployed along the Northwest (Bruckless, Donegal) and Southwest coasts of Ireland (Bantry Bay) at different depths $(0,5$ and $10 \mathrm{~m}$ ) during an AZA toxic event.

\section{Culture Extraction.}

Samples $(10 \mathrm{~mL})$ of cultures of an Irish strain $\left(\mathrm{SM} 2^{6}\right)$ and a North Sea strain $\left(3 \mathrm{D} 9^{36}\right)$ of $A$. spinosum were loaded onto solid-phase extraction (SPE) cartridges (Oasis HLB, $100 \mathrm{mg}$ ), washed with $\mathrm{MeOH} / \mathrm{H}_{2} \mathrm{O}(1: 9,5 \mathrm{~mL})$, and eluted with $\mathrm{MeOH}(3 \mathrm{~mL})$. The eluate was evaporated under a stream of nitrogen, taken up in $250 \mu \mathrm{L} \mathrm{MeOH}$, and analysed by LCMS/MS (Method A).

\section{Shellfish Extraction.}

Samples were prepared as described in Kilcoyne et al. ${ }^{18}$ The extracts were analysed by LCMS/MS (Method A). 


\section{Isolation and Purification of 3 and 4.}

Initial isolation steps were performed from bulk cultures of the 3D9 strain of $A$. spinosum as described by Jauffrais et al. ${ }^{24} \mathrm{HP}-20$ resin extracts were combined, evaporated in vacuo, and partitioned between EtOAc $(150 \mathrm{~mL})$ and aqueous $\mathrm{NaCl}(1 \mathrm{M}, 50 \mathrm{~mL})$. The EtOAc fraction was evaporated to dryness in vacuo, the residue dissolved in EtOAc $(20 \mathrm{~mL})$, and $4 \mathrm{~g}$ of silica gel added. The sample was then carefully evaporated to dryness in vacuo, mixed to a fine powder, and loaded onto a silica gel $(6 \mathrm{~g})$ column (with dimensions of $3 \times 5 \mathrm{~cm}$ ). Vacuum-assisted elution was performed successively with hexane, EtOAc, EtOAc/MeOH $(9: 1,7: 3$, and 1:1), and $\mathrm{MeOH}$ (30 $\mathrm{mL}$ of each, all containing $0.1 \%$ acetic acid except for hexane). The 7:3 EtOAc/MeOH fraction, which flow-injection analysis (FIA)-MS/MS (method B) showed to contain the AZAs, was evaporated in vacuo, and the sample loaded in $\mathrm{CH}_{3} \mathrm{CN} / \mathrm{H}_{2} \mathrm{O}(6: 4$, plus $0.1 \%$ triethylamine $)$ onto a column packed with Phenyl-Hexyl $(19.9 \times 2$ $\mathrm{cm})$. The sample was eluted with $\mathrm{CH}_{3} \mathrm{CN} / \mathrm{H}_{2} \mathrm{O}(7: 13$, plus $0.1 \%$ triethylamine) at $4 \mathrm{~mL} / \mathrm{min}$, and $5 \mathrm{~mL}$ fractions were collected. Appropriate fractions were combined (4 and 1, fractions 15-18; and 2 and 3, fractions 19-25) based on FIA-MS/MS analysis (Method B).

Final purification of 3 and $\mathbf{4}$ was achieved by semi-preparative LC (Agilent 1200) with photodiode array (PDA) detection $(210 \mathrm{~nm})$ using a Cosmosil C18, $5 \mu \mathrm{m}, 250 \times 4.6 \mathrm{~mm}$, Nacalai tesque column at $30{ }^{\circ} \mathrm{C}$ eluted with $\mathrm{CH}_{3} \mathrm{CN} / \mathrm{H}_{2} \mathrm{O}(13: 7$, plus $2 \mathrm{mM}$ ammonium acetate) at $1 \mathrm{~mL} / \mathrm{min}$. Purified 3 and 4 were recovered by evaporation to $\sim 20 \% \mathrm{CH}_{3} \mathrm{CN}$, loading onto SPE cartridges (Oasis $\mathrm{HLB}, 200 \mathrm{mg}$ ), washing with $\mathrm{MeOH} / \mathrm{H}_{2} \mathrm{O}(1: 9,10 \mathrm{~mL}$ ) to remove the buffer, and eluting step-wise with $\mathrm{MeOH} / \mathrm{H}_{2} \mathrm{O}(4: 6,6: 4,8: 2,10: 0,20 \mathrm{~mL}$ each) with $>95 \%$ of 3 and 4 recovered in the $8: 2 \mathrm{MeOH} / \mathrm{H}_{2} \mathrm{O}$. Removal of solvent by evaporation in vacuo afforded purified 3 and 4 as white solids (700 $\mu \mathrm{g}$ and $250 \mu \mathrm{g}$ respectively).

AZA33 (3). white, amorphous solid; ${ }^{1} \mathrm{H}$ and ${ }^{13} \mathrm{C}$ data $\left(\mathrm{CD}_{3} \mathrm{OD}, 600 \mathrm{MHz}\right)$, see Table 1; HRESIMS $m / z 716.4759[\mathrm{M}+\mathrm{H}]^{+}$(calcd for $\mathrm{C}_{41} \mathrm{H}_{66} \mathrm{NO}_{9}, 716.4738$ ).

AZA34 (4). white, amorphous solid; ${ }^{1} \mathrm{H}$ and ${ }^{13} \mathrm{C}$ data $\left(\mathrm{CD}_{3} \mathrm{OD}, 600 \mathrm{MHz}\right)$, see Table 1; HRESIMS $m / z 816.4900[\mathrm{M}+\mathrm{H}]^{+}$(calcd for $\mathrm{C}_{45} \mathrm{H}_{70} \mathrm{NO}_{12}, 816.4898$ ).

\section{LC-MS Experiments.}

Method $A$. Recoveries were determined by quantitative analysis of fractions on a Waters 2695 LC coupled to a Micromass TSQ Ultima operated in SRM mode for the following transitions: $\quad \mathrm{m} / \mathrm{z} \quad 842.5 \rightarrow 824.5 / 362.3 \quad(\mathbf{1}) ; \quad \mathrm{m} / \mathrm{z} \quad 856.5 \rightarrow 838.5 / 362.3 \quad(2) ; \quad \mathrm{m} / \mathrm{z}$ $716.5 \rightarrow 698.5 / 362.3(3) ; \mathrm{m} / \mathrm{z} 816.5 \rightarrow 798.5 / 362.3(4)$; and $\mathrm{m} / \mathrm{z} 830.5 \rightarrow 812.5 / 362.5$ (AZA35). The cone voltage was $60 \mathrm{~V}$, collision energy was $50 \mathrm{~V}$, the cone and desolvation gas flows were set at 100 and $800 \mathrm{~L} / \mathrm{h}$, respectively, and the source temperature was $150{ }^{\circ} \mathrm{C}$.

Binary gradient elution was used, with mobile phase $A$ consisting of $\mathrm{H}_{2} \mathrm{O}$ and mobile phase $\mathrm{B}$ of $95 \% \mathrm{CH}_{3} \mathrm{CN}$ in $\mathrm{H}_{2} \mathrm{O}$ (both containing $2 \mathrm{mM}$ ammonium formate and $50 \mathrm{mM}$ formic acid). Chromatography was performed with a Hypersil BDS C8 column $(50 \times 2.1 \mathrm{~mm}, 3 \mu \mathrm{m}$, with a $10 \times 2.1 \mathrm{~mm}$ guard column of the same stationary phase) (Thermo Scientific). The gradient was from $30-90 \%$ B over $8 \mathrm{~min}$ at $0.25 \mathrm{~mL} / \mathrm{min}$, held for $5 \mathrm{~min}$, then held at $100 \% \mathrm{~B}$ at $0.4 \mathrm{~mL} / \mathrm{min}$ for $5 \mathrm{~min}$, returned to the initial conditions and held for $4 \mathrm{~min}$ to equilibrate the system. The injection volume was $5 \mu \mathrm{L}$ and the column and sample temperatures were $25{ }^{\circ} \mathrm{C}$ and $6{ }^{\circ} \mathrm{C}$, respectively.

Method B. Qualitative analysis of fractions for AZAs was performed by FIA-MS/MS using a Micromass QToF Ultima coupled to a Waters 2795 LC. Samples $(2 \mu \mathrm{L})$ were injected directly (no column) into the mass spectrometer, monitoring for the precursor ions.

Method C. Purity was assessed on a Micromass QToF Ultima coupled to a Waters 2795 LC by running MS scans $(\mathrm{m} / \mathrm{z} 100-1000)$ using the same chromatographic conditions as method 
B. Structure analysis of AZA analogues was performed via product ion scans, where the precursor ions were selected and then fragmented, for all the known AZA analogues.

Method $D$. Accurate mass measurements were performed on a Waters Acquity UPLC coupled to a Xevo G2-S QToF operated in $\mathrm{MS}^{\mathrm{e}}$ mode, scanning from 100-1200 $\mathrm{m} / \mathrm{z}$ and using leucine enkephalin as the reference compound. The cone voltage was $40 \mathrm{~V}$, collision energy was $50 \mathrm{~V}$, the cone and desolvation gas flows were set at 100 and $1000 \mathrm{~L} / \mathrm{h}$, respectively, and the source temperature was $120^{\circ} \mathrm{C}$.

Chromatography was performed with an Acquity UPLC BEH C18 $(50 \times 2.1 \mathrm{~mm}, 1.7 \mu \mathrm{m})$ column (Waters), using the same mobile phase described in Method $A$. The gradient was from $30-90 \%$ B over $2 \mathrm{~min}$ at $0.4 \mathrm{~mL} / \mathrm{min}$, held for $2 \mathrm{~min}$, and returned to the initial conditions and held for $1 \mathrm{~min}$ to equilibrate the system. The injection volume was $5 \mu \mathrm{L}$ and the column and sample temperatures were $25^{\circ} \mathrm{C}$ and $6{ }^{\circ} \mathrm{C}$, respectively.

Method E. The samples were analysed using a neutral eluent to enable the separation of 37epimers ${ }^{18}$ of $\mathbf{3}$ and $\mathbf{4}$. Separation was performed using the same column and conditions as in Method D, except that the mobile phase was $\mathrm{H}_{2} \mathrm{O}(A)$ and $\mathrm{CH}_{3} \mathrm{CN} / \mathrm{H}_{2} \mathrm{O}$ (95:5) (B), each containing $5 \mathrm{mM}$ ammonium acetate ( $\mathrm{pH} 6.8)$.

Method $F$. For the relative molar response study, accurate AZA working standards $(1.3 \mu \mathrm{M}$ for $1,1.6 \mu \mathrm{M}$ for 3 , and $1.3 \mu \mathrm{M}$ for 4 ) were prepared by diluting purified AZAs in high purity degassed methanol and quantitating by qNMR. Samples were analysed using gradient and isocratic LC-MS/MS methods with acidic eluents (Method A). Analysis was performed on an Agilent 1200 LC system with the same Luna column described in Method E, eluted at 0.3 $\mathrm{mL} / \mathrm{min}$, connected to an API4000 QTRAP mass spectrometer (AB Sciex) equipped with a Turbospray ionization source. The MS was operated in positive ion mode and SRM transitions were as follows: $\mathrm{m} / \mathrm{z} \quad 842.5 \rightarrow 824.5 / 672.5 / 462.3 / 362.3 \quad$ (1); $\mathrm{m} / \mathrm{z}$ $716.5 \rightarrow 698.5 / 462.3 / 362.3(3)$ and $m / z$ 816.5 $\rightarrow 798.5 / 672.5 / 362.3$ (4). For SIM experiments, $\mathrm{m} / \mathrm{z} 842.5,716.5$ and $816.5\left([\mathrm{M}+\mathrm{H}]^{+}\right)$were analysed. Typical parameters were $5500 \mathrm{~V}$ electrospray voltage, $400{ }^{\circ} \mathrm{C}$ source temperature, $70 \mathrm{eV}$ declustering potential and collision energies of 45 to $70 \mathrm{eV}$ (where applicable). The injection volume was 1-5 $\mu \mathrm{L}$ and the column and sample temperatures were $25{ }^{\circ} \mathrm{C}$ and $6{ }^{\circ} \mathrm{C}$, respectively. Method $\mathrm{F}(\mathrm{i})$. Gradient elution used a linear gradient from $25-100 \%$ B over 5 min and held at $100 \%$ B for 2 min before reequilibration for the next run. Method F(ii). Used isocratic elution with $60 \% \mathrm{~B}$.

\section{Stability Studies.}

Purified samples of 1, 3 and 4 were combined and aliquots (in $\mathrm{MeOH}$ ) were stored in flamesealed ampoules (under nitrogen) at $-18{ }^{\circ} \mathrm{C},+20^{\circ} \mathrm{C}$ and $+40{ }^{\circ} \mathrm{C}$ for up to 7 days. The study was performed isochronously, ${ }^{38}$ and samples were analyzed simultaneously by LC-MS/MS (Method A) with specimens stored at $-80^{\circ} \mathrm{C}$ used as controls.

\section{Periodate Cleavage.}

Aliquots $(100 \mu \mathrm{L})$ of purified and diluted samples $(\sim 100 \mathrm{ng} / \mathrm{mL})$ of $\mathbf{1}, \mathbf{3}$ and 4 were oxidised by adding $50 \mu \mathrm{L}$ of $0.2 \mathrm{M} \mathrm{NalO}_{4}$. The samples were analysed immediately by LC-MS/MS (Method C) but with an additional trace for the oxidised AZA product ( $\mathrm{m} / \mathrm{z} 448.3$ ).

\section{Methylation with Diazomethane.}

To determine whether a carboxylic acid group was present, purified 3 and 4 ( $60 \mathrm{ng})$ samples were reacted with diazomethane. The samples were added to the outside tube of an Aldrich diazomethane generator with System 45 connection, and $1 \mathrm{~mL} \mathrm{MeOH}$ and $1.5 \mathrm{~mL}$ diethyl ether were added. Diazomethane was generated in the inner tube of the apparatus and allowed to react in situ with the extract. After reacting for $45 \mathrm{~min}$ at $0{ }^{\circ} \mathrm{C}$ with occasional 
swirling, the extracts were transferred to a glass vial, evaporated to dryness under a stream of $\mathrm{N}_{2}$, and residues dissolved in $\mathrm{MeOH}(1 \mathrm{~mL}$ ) for LC-MS/MS (Method C).

\section{NMR Experiments.}

Structural determinations were performed by analysis of ${ }^{1} \mathrm{H}$, COSY, TOCSY, SELTOCSY, NOESY, ROESY, SELROESY, ${ }^{13} \mathrm{C}$, DEPT135, HSQC and HMBC spectra. Samples of 1 (1

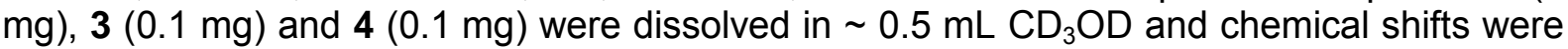
referenced to internal $\mathrm{CHD}_{2} \mathrm{OD}(3.31 \mathrm{ppm})$, or $\mathrm{CD}_{3} \mathrm{OD}(49.0 \mathrm{ppm})$. Single- or doublefrequency pre-saturation of solvent resonances was performed using continuous wave and/or excitation sculpting as required.

Quantitation of pure 3 and 4 was performed on aliquots in $\mathrm{CD}_{3} \mathrm{OH}$. The sample was run against external standards of caffeine in $\mathrm{H}_{2} \mathrm{O}(4.01 \mathrm{mM})$ as described previously. ${ }^{39}$

\section{Toxins and Other Materials.}

All solvents (pesticide analysis grade) were from Labscan and Caledon. Distilled $\mathrm{H}_{2} \mathrm{O}$ was further purified using a Barnstead nanopure diamond UV purification system (Thermo Scientific). Sodium chloride $(99+\%)$, triethylamine $(99 \%)$, ammonium acetate $(97+\%)$, ammonium formate (reagent grade), formic acid (>98\%), silica gel (10-40 $\mu$ m, type $\mathrm{H}$ ), sodium periodate and $\mathrm{CD}_{3} \mathrm{OD}(100.0$ atom- $\%$ D) were from Sigma-Aldrich. Sephadex LH-20 was from GE Healthcare, LiChroprep RP C8 $(25-40 \mu \mathrm{m})$ was from Merck, Luna PhenylHexyl $(15 \mu \mathrm{m})$ was from Phenomenex, $\mathrm{CD}_{3} \mathrm{OH}(99.5$ atom-\% D) for qNMR was from Cambridge Isotope Laboratories. AZA CRMs were obtained from the National Research Council of Canada.

\section{Toxicology.}

Cell Culturing. Human Jurkat E6-1 T lymphocyte cells (American Type Culture Collection TIB-152) were grown as described by Twiner et al. ${ }^{40}$ Briefly, cells were grown in RPMI-1640 medium (cat. \#11875-093, Invitrogen) supplemented with $10 \%(\mathrm{v} / \mathrm{v})$ fetal bovine serum (FBS; cat. \#26140, Invitrogen) and maintained in a humidified incubator (Sanyo 18AIC-UV) with 5\% $\mathrm{CO}_{2}$ in air at $37^{\circ} \mathrm{C}$. Cells were subcultured with fresh medium at an inoculum ratio of $1: 4$ every 3 to 4 days by transferring $2.5 \mathrm{~mL}$ of cells to $7.5 \mathrm{~mL}$ of fresh supplemented medium in $75 \mathrm{~cm}^{3}$ screw cap culture flasks.

Cytotoxicity Assay. The effect of the AZA analogues on the viability of Jurkat T lymphocyte cells was determined. Exponentially growing cells were seeded in $100 \mu \mathrm{L}$ of the supplemented medium at a density of 30,000 cells per well in black, sterile, 96-well culture plates for 12-18 $\mathrm{h}$ to allow for recovery and settling. AZA analogues were added at various concentrations and assessed for cytotoxicity after 24,48 , or $72 \mathrm{~h}$ of exposure. Parallel controls of equivalent amounts of phosphate buffered saline/MeOH were used to normalize the viability data for each treatment. Cellular viability/cytotoxicity was assessed using the MTS (3-(4,5-dimethylthiazol-2-yl)-5-(3-carboxymethoxyphenyl)-2-(4-sulfophenyl)-2Htetrazolium) assay (Promega Biosciences, cat. no. G5421). Like other tetrazolium-based assays, MTS in the presence of an electron coupling reagent (phenazine methosulfate; PMS) measures cellular viability by determining the activity of mitochondrial dehydrogenases. ${ }^{41}$ As a substrate for dehydrogenases, MTS becomes reduced into a soluble, purple dye that can be quantitated colorimetrically to determine the relative level of cellular viability/cytotoxicity per well. Following exposure of the cells to the AZA analogues for the specified time, each well received $10 \mu \mathrm{L}$ of a PMS/MTS (1:20) solution (final concentrations of 7.9 and 158.5 $\mu \mathrm{g} / \mathrm{mL}$, respectively). Cells were incubated for $4 \mathrm{~h}$, after which absorbance readings at 485 $\mathrm{nm}$ were obtained using a FluoStar microplate reader (BMG Lab Technologies). Data are presented as means \pm SE of three separate experiments $(n=3)$. In addition, each cytotoxicity 
experiment was performed using duplicate wells. Cytotoxicity data were blank-corrected and normalized to the control (\% viability). $\mathrm{EC}_{50}$ and $95 \%$ confidence intervals were calculated using three-parameter, variable slope, non-linear regression analysis (GraphPad Prism, ver. 5.0c).

\section{Acknowledgements}

We thank the biotoxin chemistry team at the Marine Institute, Galway, R. Salas and S. Shannon of the Marine Institute (Galway, Ireland) for providing samples of A. spinsoum, W. Egge-Jacobsen (University of Oslo, Norway) for assistance with Orbitrap LC-MS analysis, and the staff of Biotoxin Metrology at NRC (Halifax, Nova Scotia, Canada), in particular, M. A. Quilliam and S. D. Giddings.

\section{Associated content}

\section{Supporting Information}

Graphs and LC-MS chromatograms from the stability study of 1, 3 and 4; mass spectra of 3 and 4 and their epimers; NMR spectra of $\mathbf{3}$ and $\mathbf{4}$ and detailed NMR tables for 1, 3 and $\mathbf{4}$. This material is free of charge via the Internet at http://pubs.acs.org.

\section{Author information}

\section{Corresponding author}

*Tel: +353 91 387376. Fax: +35391 387201. Email: jane.kilcoyne@marine.ie

\section{Funding}

This project (PBA/AF/08/001(01) was carried out under the Sea Change strategy with the support of the Marine Institute and the Marine Research Sub-Programme of the National Development Plan 2007-2013, co-financed under the European Regional Development Fund and supported in part by a Marie Curie International Incoming Fellowship within the seventh European Community Framework Programme (FP7/2007-2013) under grant agreement no. 221117.

\section{Notes}

The authors declare no competing financial interest. 


\section{References}

(1) Rehmann, N., Hess, P., and Quilliam, M. A. Rapid Commun. Mass Spectrom. 2008, 22, 549-558.

(2) Twiner, M. J., Rehmann, N., Hess, P., and Doucette, G. J. Mar. Drugs 2008, 6, 39-72.

(3) Anon. (2011) Commission Regulation (EU) No 15/2011 of 10th January 2011 amending Regulation (EC) No 2074/2005 as regards recognised testing methods for detecting marine biotoxins in live bivalve molluscs. L6/3-6.

(4) Krock, B., Tillmann, U., John, U., and Cembella, A. D. Harmful Algae 2009, 8, 254263.

(5) McCarron, P., Kilcoyne, J., Miles, C. O., and Hess, P. J. Agric. Food Chem. 2009, 57, 160-169.

(6) Salas, R., Tillmann, U., John, U., Kilcoyne, J., Burson, A., Cantwell, C., Hess, P., Jauffrais, T., and Silke, J. Harmful Algae 2011, 10, 774-783.

(7) Jauffrais, T., Contreras, A., Herrenknecht, C., Truquet, P., Séchet, V., Tillmann, U., and Hess, P. Aquat. Toxicol. 2012, 124-125, 179-187.

(8) Colman, J. R., Twiner, M. J., Hess, P., McMahon, T., Satake, M., Yasumoto, T., Doucette, G. J., and Ramsdell, J. S. Toxicon 2005, 45, 881-890.

(9) Ito, E., Satake, M., Ofuji, K., Higashi, M., Harigaya, K., McMahon, T., and Yasumoto, T. Toxicon 2002, 40, 193-203.

(10) Aasen, J. A. B., Espenes, A., Hess, P., and Aune, T. Toxicon 2010, 56, 1419-1425.

(11) Furey, A., O'Doherty, S., O'Callaghan, K., Lehane, M., and James, K. J. Toxicon 2010, 56, 173-190.

(12) Twiner, M. J., El-Ladki, R., Kilcoyne, J., and Doucette, G. J. Chem. Res. Toxicol. 2012, 25, 747-754.

(13) Twiner, M. J., Hanagriff, J. C., Butler, S., Madhkoor, A. K., and Doucette, G. J. Chem. Res. Toxicol. 2012, 25, 1493-1501.

(14) Satake, M., Ofuji, K., Naoki, H., James, K. J., Furey, A., McMahon, T., Silke, J., and Yasumoto, T. J. Am. Chem. Soc. 1998, 120, 9967-9968.

(15) Ofuji, K., Satake, M., McMahon, T., Silke, J., James, K. J., Naoki, H., Oshima, Y., and Yasumoto, T. Nat. Toxins 1999, 7, 99-102.

(16) Ofuji, K., Satake, M., McMahon, T., James, K. J., Naoki, H., Oshima, Y., and Yasumoto, T. Biosci. Biotechnol. Biochem. 2001, 65, 740-742.

(17) Kilcoyne, J., Keogh, A., Clancy, G., LeBlanc, P., Burton, I., Quilliam, M. A., Hess, P., and Miles, C. O. J. Agric. Food Chem. 2012, 60, 2447-2455.

(18) Kilcoyne, J., McCarron, P., Twiner, M. J., Nulty, C., Wilkins, A. L., Rise, F., Quilliam, M. A., and Miles, C. O. Chem. Res. Toxicol. 2014, 27, 587-600.

(19) Perez, R., Rehmann, N., Crain, S., LeBlanc, P., Craft, C., MacKinnon, S., Reeves, K., Burton, I., Walter, J. A., Hess, P., Quilliam, M. A., and Melanson, J. Anal. Bioanal. Chem. 2010, 398, 2243-2252.

(20) Laycock, M., Thibault, P., Ayer, S., and Walter, J. Nat. Toxins 1994, 2, 175-183.

(21) Miles, C. O., Wilkins, A. L., Munday, R., Dines, M. H., Hawkes, A. D., Briggs, L. R., Sandvik, M., Jensen, D. J., Cooney, J. M., and Holland, P. T. Toxicon 2004, 43, 1-9.

(22) Abraham, A., Plakas, S. M., Wang, Z., Jester, E., El Said, K. R., Granade, H. R., Henry, M. S., Blum, P. C., Pierce, R. H., and Dickey, R. W. Toxicon 2006, 48, 104115.

(23) Ueoka, R., Ito, A., Izumikawa, M., Maeda, S., Takagi, M., Shin-ya, K., Yoshida, M., Van Soest, R. W. M., and Matsunaga, S. Toxicon 2009, 53, 680-684.

(24) Jauffrais, T., Kilcoyne, J., Séchet, V., Herrenknecht, C., Truquet, P., Hervé, F., Bérard, J. B., Nulty, C., Taylor, S., Tillmann, U., Miles, C. O., and Hess, P. Mar. Drugs 2012, 10, 1360-1382.

(25) Krock, B., Tillmann, U., Voß, D., Koch, B. P., Salas, R., Witt, M., Potvin, É., and Jeong, H. J. Toxicon 2012, 60, 830-839.

(26) Gu, H., Luo, Z., Krock, B., Witt, M., and Tillmann, U. Harmful Algae 2013, 21-22, 6475. 
(27) Percopo, I., Siano, R., Rossi, R., Soprano, V., Sarno, D., and Zingone, A. J. phycol. 2013, 49, 950-966.

(28) Fux, E., Marcaillou, C., Mondeguer, F., Bire, R., and Hess, P. Harmful Algae 2008, 7, 574-583.

(29) HABs,

database.

http://www.marine.ie/home/publicationsdata/data/Habs+Search+Database/HabsSearc h.htm. Accessed 14 May 2014.

(30) Tillmann, U., Soehner, S., Nézan, E., and Krock, B. Harmful Algae 2012, 20, 142-155.

(31) Jauffrais, T., Kilcoyne, J., Herrenknecht, C., Truquet, P., Séchet, V., Miles, C. O., and Hess, P. Toxicon 2013, 65, 81-89.

(32) McCarron, P., Giddings, S. D., and Quilliam, M. A. Anal. Bioanal. Chem. 2011, 400, 835-846.

(33) Hess, P., McCarron, P., Krock, J., Kilcoyne, J., and Miles, C. O. (2014) Azaspiracids: chemistry, biosynthesis, metabolism and detection, in Seafood and Freshwater Toxins (Botana, L. M. , Ed.) 3rd ed., pp 799-821, CRC Press, Boca Raton, FL.

(34) Kellmann, R., Stüken, A., Orr, R. J., Svendsen, H. M., and Jakobsen, K. S. Mar. Drugs 2010, 8, 1011-1048.

(35) Twiner, M. J., Doucette, G. J., Rasky, A., Huang, P. X., Roth, B. L., and Sanguinetti, M. C. Chem. Res. Toxicol. 2012, 25, 1975-1984.

(36) Tillmann, U., Elbrächter, M., Krock, B., John, U., and Cembella, A. D. Eur. J. Phycol. 2009, 44, 63-79.

(37) Fux, E., Bire, R., and Hess, P. Harmful Algae 2009, 8, 523-537.

(38) Lamberty, A., Schimmel, H., and Pauwels, J. J. Anal. Chem. 1998, 360, 359-361.

(39) Burton, I., Quilliam, M. A., and Walter, J. A. Anal. Chem. 2005, 77, 3123-3131.

(40) Twiner, M. J., Hess, P., Bottein Dechraoui, M. Y., McMahon, T., Samons, M. S., Satake, M., Yasumoto, T., Ramsdell, J. S., and Doucette, G. J. Toxicon 2005, 45, 891-900.

(41) Mosmann, T. J. Immuno. Methods 1983, 65, 55-63.

(42) Jauffrais, T., Herrenknecht, C., Sechet, V., Sibat, M., Tillmann, U., Krock, B., Kilcoyne, J., Miles, C. O., McCarron, P., Amzil, Z., and Hess, P. Anal. Bioanal. Chem 2012, 403, 833-846. 
Table 1. Exact Masses of $[\mathrm{M}+\mathrm{H}]^{+}$lons and Calculated Molecular Formulae for AZA1 (1), -2 (2) and -33-35 (3, 4 and AZA35) in an A. spinosum (3D9) HP-20 Permeate Extract

\begin{tabular}{|c|c|c|c|c|}
\hline AZA & $\begin{array}{c}\text { Molecular } \\
\text { Formula }\end{array}$ & $\begin{array}{c}\text { Measured } \\
\mathrm{m} / z \\
{[\mathrm{M}+\mathrm{H}]^{+}}\end{array}$ & $\begin{array}{c}\text { Rings }+ \\
\text { double } \\
\text { bonds }\end{array}$ & $\begin{array}{c}\Delta \\
(\mathrm{ppm})\end{array}$ \\
\hline AZA1 (1) & $\mathrm{C}_{47} \mathrm{H}_{71} \mathrm{NO}_{12}$ & 842.5052 & 13 & 0.4 \\
\hline AZA2 (2) & $\mathrm{C}_{48} \mathrm{H}_{73} \mathrm{NO}_{12}$ & 856.5195 & 13 & -1.2 \\
\hline AZA33 (3) & $\mathrm{C}_{41} \mathrm{H}_{65} \mathrm{NO}_{9}$ & 716.4759 & 10 & 3.8 \\
\hline AZA34 (4) & $\mathrm{C}_{45} \mathrm{H}_{69} \mathrm{NO}_{12}$ & 816.4900 & 12 & 0.9 \\
\hline AZA35 & $\mathrm{C}_{46} \mathrm{H}_{71} \mathrm{NO}_{12}$ & 830.5046 & 12 & -0.4 \\
\hline
\end{tabular}


Table 2. NMR Assignments $\left({ }^{1} \mathrm{H} 600 \mathrm{MHz},{ }^{13} \mathrm{C} 150 \mathrm{MHz}\right)$ for AZA1 (1), -33 (3) and -34 (4) in $\mathrm{CD}_{3} \mathrm{OD}$

\begin{tabular}{|c|c|c|c|c|c|c|}
\hline \multirow{2}{*}{ Position } & \multicolumn{2}{|r|}{$\mathbf{1}^{a}$} & \multicolumn{2}{|r|}{3} & \multicolumn{2}{|r|}{4} \\
\hline & ${ }^{13} \mathrm{C}$ & ${ }^{1} \mathrm{H}$ & ${ }^{13} \mathrm{C}$ & ${ }^{1} \mathrm{H}$ & ${ }^{13} \mathrm{C}$ & ${ }^{1} \mathrm{H}$ \\
\hline 1 & 181.2 & & & & & \\
\hline 2 & 38.1 & $2.25,2.25$ & & & & \\
\hline 3 & 30.2 & $2.33,2.33$ & & & 181.9 & \\
\hline 4 & 133.7 & 5.75 & & & 34.7 & $2.21,2.31$ \\
\hline 5 & 130.7 & 5.44 & & & 33.2 & $1.76,1.85$ \\
\hline 6 & 72.5 & 4.79 & 181.9 & & 70.5 & 4.41 \\
\hline 7 & 129.4 & 5.63 & 39.7 & $2.18,2.18$ & 130.1 & 5.70 \\
\hline 8 & 123.2 & 5.73 & 30.9 & $2.26,2.26$ & 123.3 & 5.72 \\
\hline 9 & 35.7 & $2.12,2.46$ & 131.5 & $5.48^{b}$ & 37.6 & $2.11,2.46$ \\
\hline 10 & 107.2 & & 130.8 & $5.45^{c}$ & 107.1 & \\
\hline 11 & 37.5 & $1.97,2.14$ & $34.1^{d}$ & $2.03,2.03$ & 37.6 & $1.94,2.12$ \\
\hline 12 & 33.2 & $1.66,2.33$ & $33.9^{d}$ & $2.03,2.03$ & 33.0 & $1.64,2.32$ \\
\hline 13 & 111.3 & & 133.4 & $5.50^{c}$ & 111.0 & \\
\hline 14 & 31.0 & 2.02 & 127.8 & $5.43^{b}$ & 30.9 & 2.01 \\
\hline 15 & 32.6 & $1.76,1.85$ & 40.5 & $2.17,2.24$ & 32.6 & $1.75,1.81$ \\
\hline 16 & 78.2 & 3.88 & 81.5 & 3.907 & 78.1 & 3.89 \\
\hline 17 & 73.3 & 4.23 & 30.9 & $1.55,1.92$ & 73.1 & 4.19 \\
\hline 18 & 37.3 & $1.99,2.01$ & 30.5 & $1.95,2.00$ & 38.3 & $2.02,2.02$ \\
\hline 19 & 79.2 & 4.43 & 80.3 & 4.08 & 79.2 & 4.41 \\
\hline 20 & 76.9 & 3.86 & 77.4 & 3.34 & 77.2 & 3.55 \\
\hline 21 & 100.2 & & 100.0 & & 99.5 & \\
\hline 22 & 36.6 & 2.12 & 35.7 & 2.37 & 36.3 & 2.24 \\
\hline 23 & 38.3 & $1.43,1.43$ & 39.0 & $1.39,1.39$ & 38.3 & $1.41,1.41$ \\
\hline 24 & 42.3 & 1.35 & 42.2 & 1.36 & 42.0 & 1.35 \\
\hline 25 & 79.6 & 3.98 & 79.5 & 3.911 & 79.8 & 3.93 \\
\hline 26 & 148.3 & & 148.0 & & 148.2 & \\
\hline 27 & 49.5 & $2.24,2.42$ & 49.6 & $2.15,2.34$ & 49.4 & $2.16,2.35$ \\
\hline 28 & 98.6 & & 98.0 & & 97.9 & \\
\hline 29 & 44.3 & $1.36,2.03$ & 44.7 & $1.30,1.98$ & 44.7 & $1.31,1.98$ \\
\hline 30 & 26.4 & 2.23 & 26.7 & 2.25 & 26.4 & 2.24 \\
\hline 31 & 35.4 & $1.52,1.83$ & 35.6 & $1.47,1.77$ & 35.6 & $1.48,1.78$ \\
\hline 32 & 72.8 & 4.35 & 72.7 & 4.24 & 72.8 & 4.26 \\
\hline 33 & 81.2 & 4.01 & 79.4 & 3.74 & 79.6 & 3.77 \\
\hline 34 & 74.9 & 4.98 & 75.4 & 4.81 & 75.5 & 4.82 \\
\hline 35 & 41.9 & $2.41,2.59$ & 43.0 & $1.88,2.39$ & 43.1 & $2.00,2.43$ \\
\hline 36 & 96.6 & & 95.8 & & 95.8 & \\
\hline 37 & 36.0 & 1.95 & 37.7 & 1.76 & 37.3 & 1.76 \\
\hline 38 & 38.0 & $1.28,1.67$ & 39.9 & $1.14,1.54$ & 39.8 & $1.17,1.55$ \\
\hline 39 & 29.8 & 1.85 & 31.0 & 1.69 & 31.2 & 1.68 \\
\hline 40 & 46.4 & $2.79,2.84^{e}$ & 47.4 & $2.53,2.46^{e}$ & 47.7 & $2.55,2.55$ \\
\hline 14-Me & 16.6 & 0.95 & & & 16.6 & 0.95 \\
\hline 22-Me & 16.4 & 0.91 & 16.9 & 0.89 & 16.3 & 0.89 \\
\hline 24-Me & 18.1 & 0.84 & 18.1 & 0.81 & 18.0 & 0.82 \\
\hline $26=\mathrm{CH}_{2}$ & 116.8 & $5.16,5.34^{f}$ & 115.4 & $5.07,5.27^{f}$ & 115.6 & $5.10,5.26^{t}$ \\
\hline 30-Me & 23.5 & 0.95 & 23.7 & 0.93 & 23.6 & 0.93 \\
\hline 37-Me & 15.5 & 0.96 & 16.1 & 0.86 & 16.0 & 0.88 \\
\hline 39-Me & 18.6 & 0.94 & 19.5 & 0.85 & 19.2 & 0.86 \\
\hline
\end{tabular}


${ }^{a}$ From Kilcoyne et al. ${ }^{18}$

${ }^{b}$ Decoupled by homonuclear decoupling at $2.21 \mathrm{ppm}$ (Figure 5A).

${ }^{c}$ Decoupled by homonuclear decoupling at $2.04 \mathrm{ppm}$ (Figure 5B).

${ }^{d}$ Assignments interchangeable.

${ }^{e} \mathrm{H}_{\text {axial }}, \mathrm{H}_{\text {equatorial }}$

${ }^{f} \mathrm{H}_{E}, \mathrm{H}_{Z}$ 
Table 3. Relative Molar Response Factors (Propagated Standard Deviation of the Last Significant Figure in Parentheses) of AZA33 (3) and AZA34 (4) in Relation to AZA1 (1) (1(Area/Concentration)/(3 or $\mathbf{4}($ Area/Concentration $)))^{a}$

\begin{tabular}{|l|c|c|c|c|}
\hline & \multicolumn{2}{|c|}{3} & \multicolumn{2}{c|}{} \\
\hline $\begin{array}{l}\text { MS mode } \\
\text { (ion/transition) }\end{array}$ & Gradient $^{b}$ & Isocratic $^{c}$ & Gradient $^{b}$ & Isocratic $^{c}$ \\
\hline $\mathrm{SIM}[\mathrm{M}+\mathrm{H}]^{+}$ & $1.03(2)$ & $0.97(3)$ & $1.01(3)$ & $1.05(3)$ \\
\hline $\mathrm{SRM}\left([\mathrm{M}+\mathrm{H}]^{+}-\mathrm{H}_{2} \mathrm{O}\right)$ & $1.03(11)$ & $1.05(3)$ & $1.22(9)$ & $1.17(7)$ \\
\hline $\mathrm{SRM}\left([\mathrm{M}+\mathrm{H}]^{+} \rightarrow 672\right)$ & - & - & $0.41(2)$ & $0.39(2)$ \\
\hline $\mathrm{SRM}\left([\mathrm{M}+\mathrm{H}]^{+} \rightarrow 462\right)$ & $0.77(5)$ & $0.80(5)$ & - & - \\
\hline $\mathrm{SRM}\left([\mathrm{M}+\mathrm{H}]^{+} \rightarrow 362\right)$ & $0.91(6)$ & $0.90(4)$ & $0.90(7)$ & $0.87(4)$ \\
\hline & & & & \\
\hline
\end{tabular}

${ }^{a}$ Determined by SIM and SRM LC-MS experiments using gradient and isocratic LC elution with an acidic mobile phase. ${ }^{b}$ Method F(i). ${ }^{c}$ Method F(ii). 
Table 4. Calculated $\mathrm{EC}_{50}$ Values (nM) with 95\% Confidence Intervals (Cl) and Relative Potencies (Rel. Pot.) for AZA Analogues Based on T Lymphocyte Cytotoxicity

\begin{tabular}{|c|c|c|c|c|c|c|c|c|}
\hline \multirow{2}{*}{ AZA analogue } & \multicolumn{2}{|r|}{$24 \mathrm{~h}$} & \multicolumn{2}{|r|}{$48 \mathrm{~h}$} & \multicolumn{2}{|r|}{$72 \mathrm{~h}$} & \multirow{2}{*}{$\begin{array}{c}\text { Mean } \\
\mathrm{EC}_{50}\end{array}$} & \multirow{2}{*}{$\begin{array}{l}\text { Rel. } \\
\text { Pot. }\end{array}$} \\
\hline & $\mathrm{EC}_{50}$ & $95 \% \mathrm{CI}$ & $\mathrm{EC}_{50}$ & $95 \% \mathrm{CI}$ & $\mathrm{EC}_{50}$ & $95 \% \mathrm{CI}$ & & \\
\hline 1 & 0.96 & $0.19-4.9$ & 1.10 & $0.46-2.5$ & 1.3 & $0.59-3.0$ & 1.1 & 1.0 \\
\hline 3 & 3.3 & $0.79-13$ & 5.9 & $2.4-15$ & 6.4 & $2.8-15$ & 5.2 & 0.22 \\
\hline 4 & 0.23 & $0.042-1.2$ & 0.18 & $0.098-0.34$ & 0.20 & $0.11-0.38$ & 0.20 & 5.5 \\
\hline
\end{tabular}




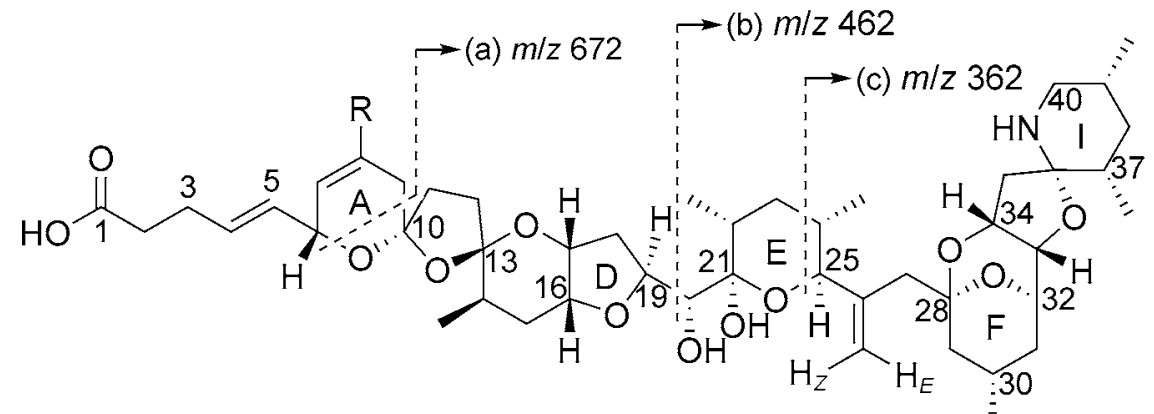

$\mathrm{R}=\mathrm{H} \quad$ Azaspiracid-1 (1)

$\mathrm{R}=\mathrm{CH}_{3}$ Azaspiracid-2 (2)

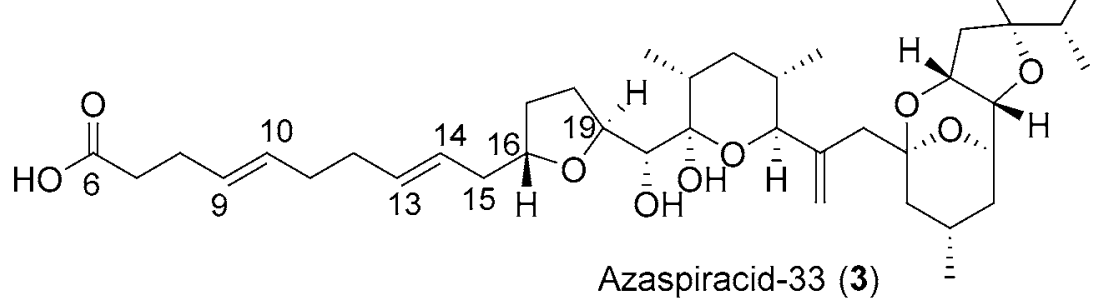

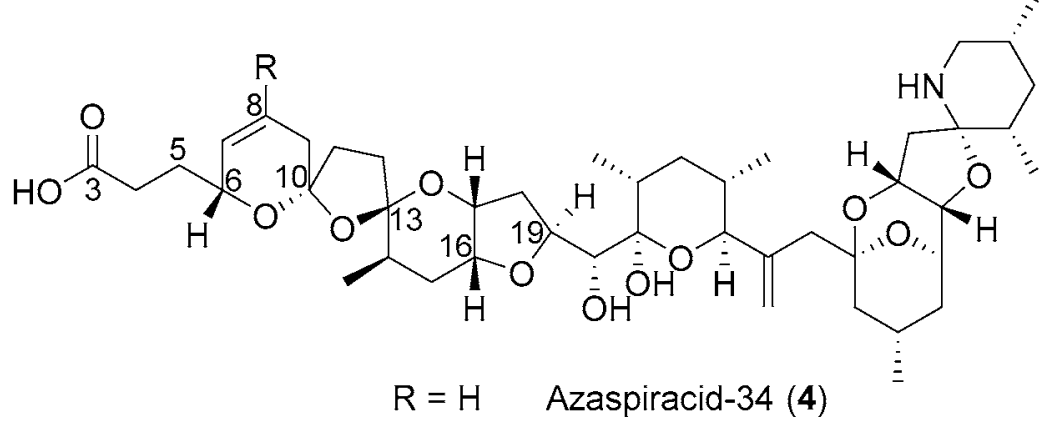

Figure 1. Structures of AZA1 (1), AZA2 (2), AZA33 (3) and AZA34 (4) including atom numbering. Note that atom numbering for 3 and 4 starts at C-6 and C-3, respectively, so that structurally related atoms in $3(\mathrm{C}-16-\mathrm{C}-40)$ and $4(\mathrm{C}-6-\mathrm{C}-40)$ retain the same atom numbering as their corresponding atoms in $\mathbf{1}$ in Table 2. Also shown are the major MS/MS fragmentation pathways for 1 and 2. Compounds 3, 4 and AZA35 showed fragmentations (b) and (c), whereas 4 and AZA35 also exhibited the RDA fragmentation pathway (a) but 3 did not (Figure 2). 


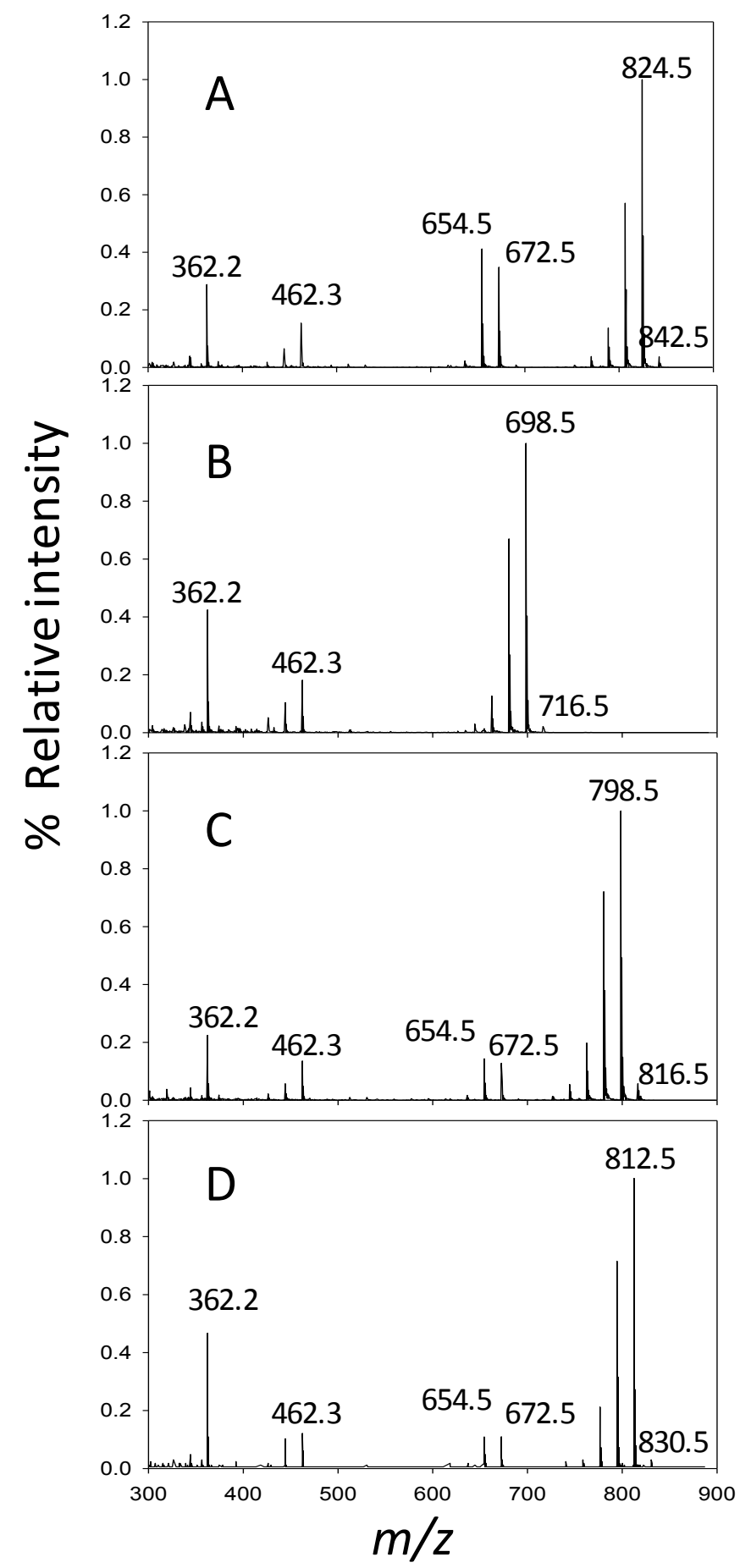

Figure 2. Mass spectra of A) AZA1 (1), B) AZA33 (3), C) AZA34 (4) and D) AZA35 at a collision energy of $50 \mathrm{eV}$ (Method C). 


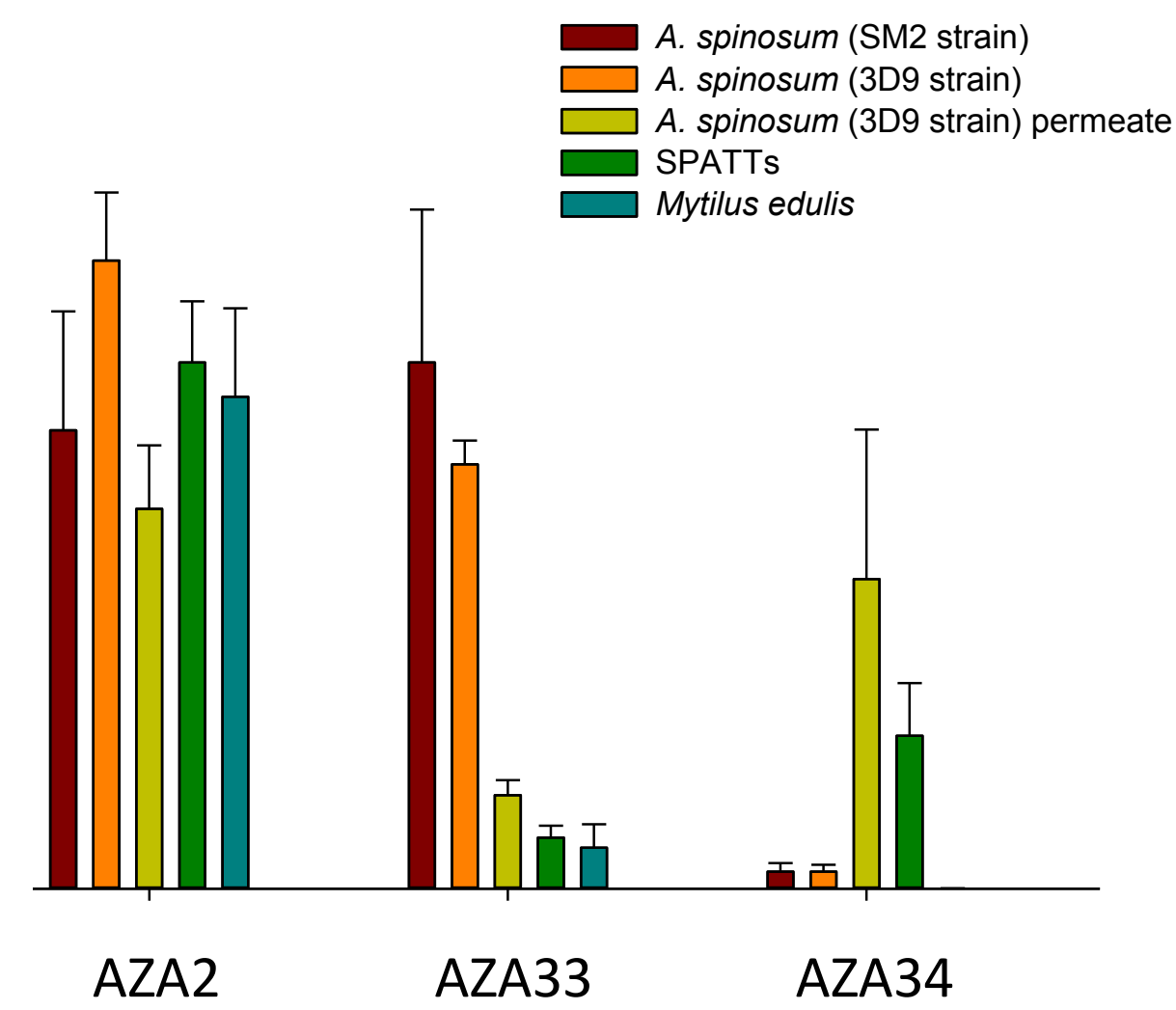

Figure 3. Ratios of AZA2 (2), AZA33 (3) and AZA34 (4) relative to AZA1 (1) detected by LCMS/MS in $A$. spinosum SM2 $(n=10), A$. spinosum 3D9 $(n=36), A$. spinosum permeate $(n=3)$, SPATTs $(\mathrm{n}=7)$ and shellfish (Mytilus edulis, $\mathrm{n}=20$ ). 


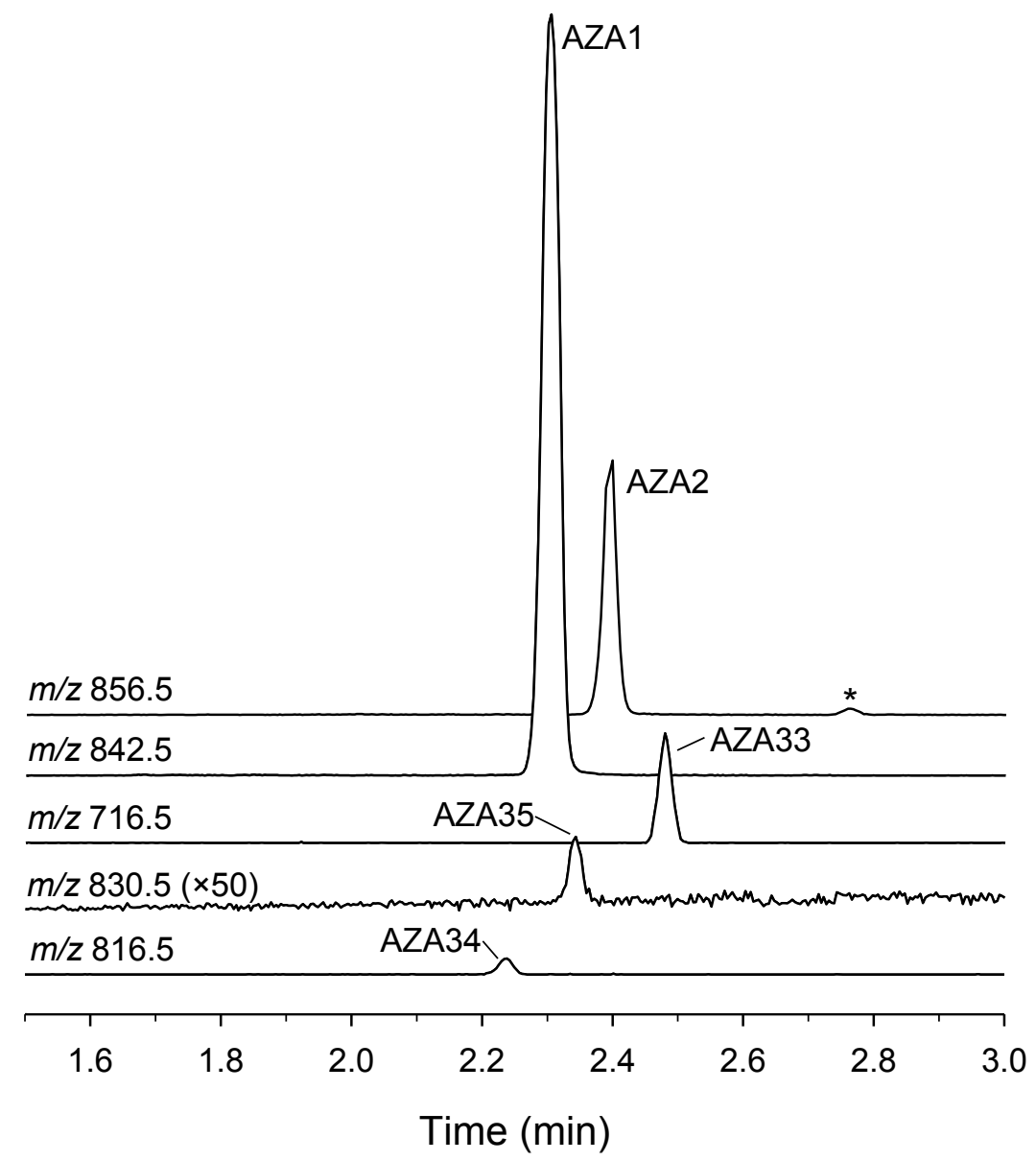

Figure 4. LC-MS chromatogram (Method D) of an HP-20 resin permeate extract from a bulk culture of $A$. spinosum showing peaks for AZA34 (4), AZA1 (1), AZA35, AZA2 (2) and AZA33 (3). Peak marked with * corresponds to AZA1 methyl ester. ${ }^{42}$ 
(A) Decoupling $2.21 \mathrm{ppm}$

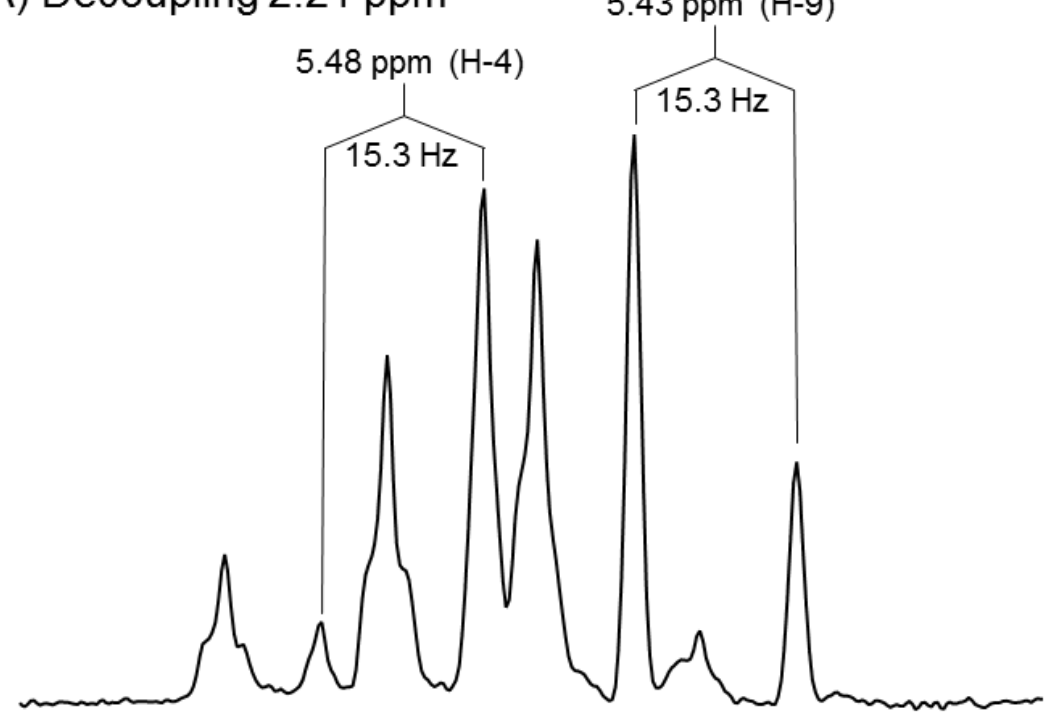

(B) Decoupling $2.03 \mathrm{ppm}$

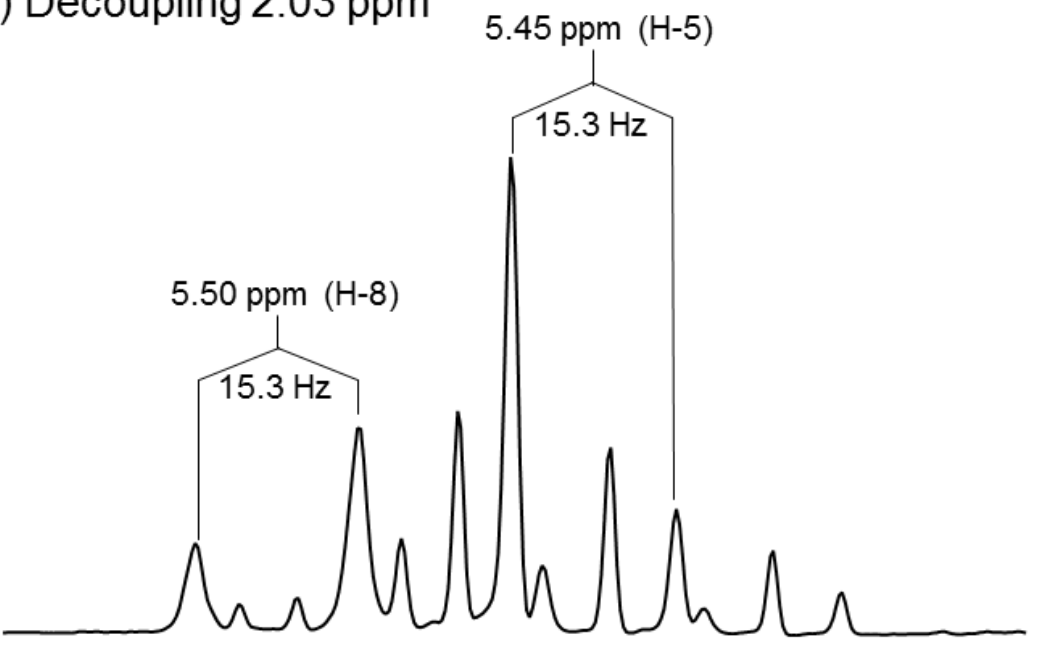

(C) No decoupling

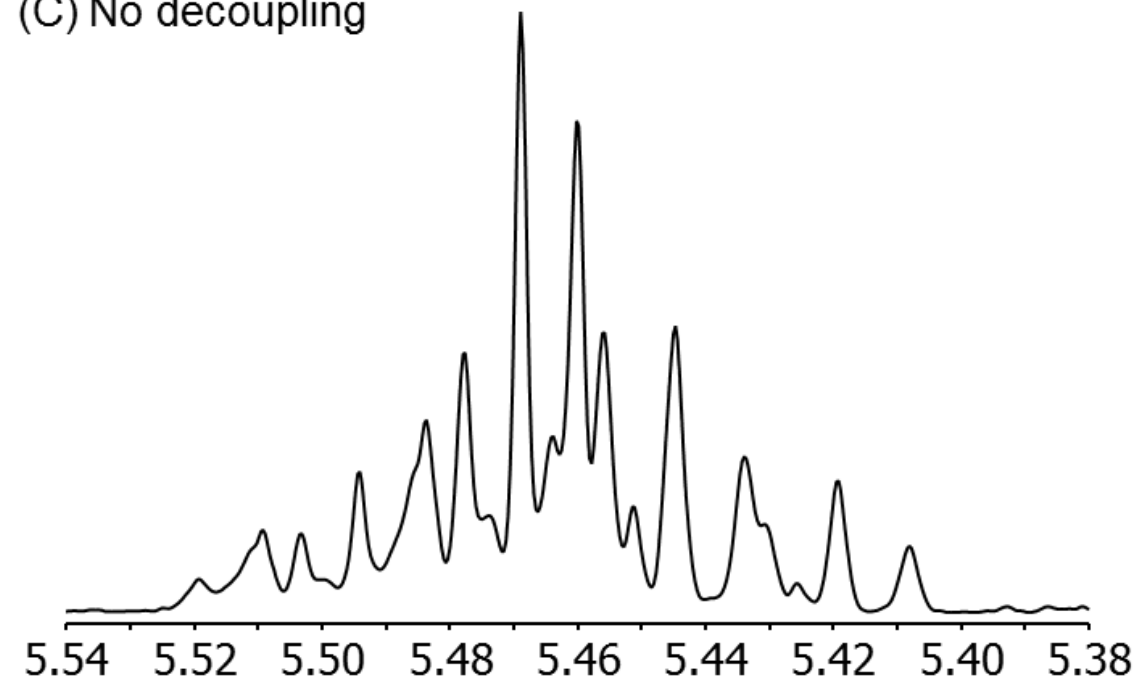

Figure 5. ${ }^{1} \mathrm{H}$ NMR spectra of AZA33 (3) from $5.38-5.54 \mathrm{ppm}$, showing the side-chain olefinic protons $(\mathrm{H}-9, \mathrm{H}-10, \mathrm{H}-13$ and $\mathrm{H}-14$ ), with: (A) high-power decoupling at $2.21 \mathrm{ppm}$ (decoupling 2.16-2.26 ppm ( $\mathrm{H}-7, \mathrm{H}-8$, and $\mathrm{H}-15)$ ); (B) low power decoupling at 2.03 ppm (decoupling $\mathrm{H}-11$ and $\mathrm{H}-12$ ), and; (C) no decoupling. 


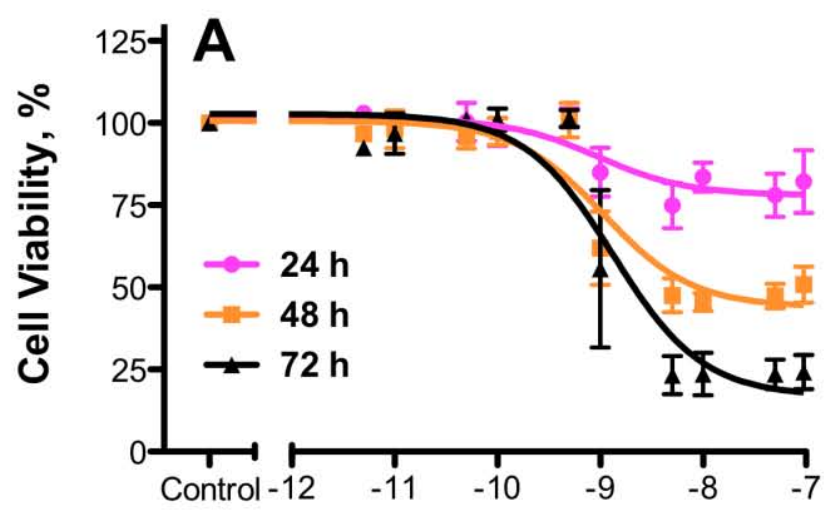

AZA1 concentration $(\log M)$

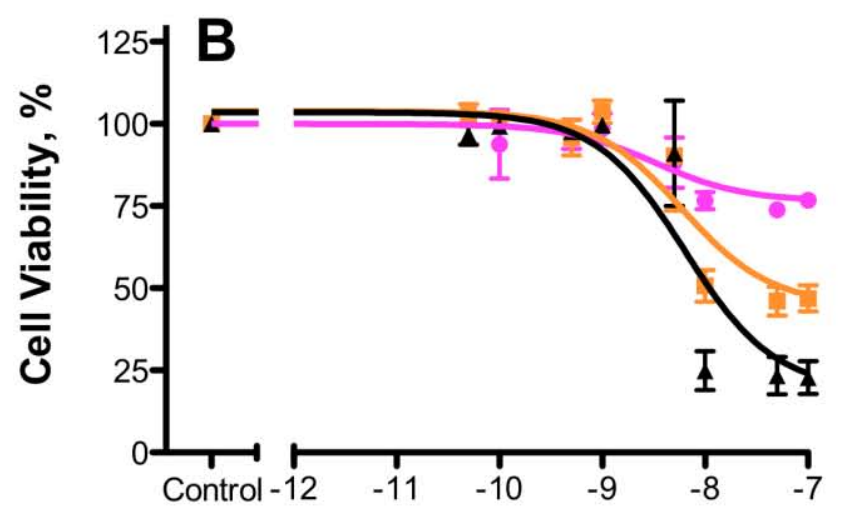

AZA33 concentration ( $\log M)$

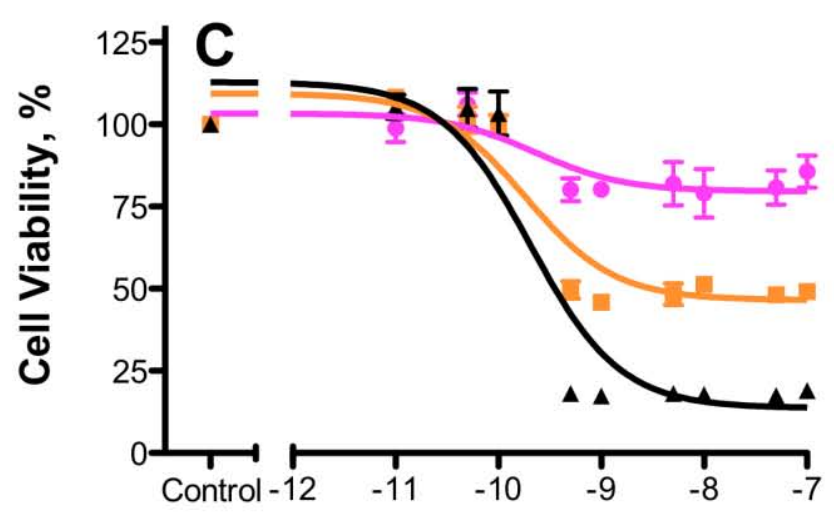

AZA34 concentration ( $\log M)$

Figure 6. Effect of $A Z A$ analogues on $T$ lymphocyte cell viability. Jurkat $T$ cells were exposed to various concentrations of (A) AZA1 (1), (B) AZA33 (3), and (C) AZA34 (4) for 24, 48, or $72 \mathrm{~h}$ and viability was assessed using the MTS assay. All data (mean $\pm S E ; n=3$ ) were normalized to the control $(10 \% \mathrm{MeOH}$ vehicle). Non-linear, three parameter dose-response (variable slope) analysis was performed and $\mathrm{EC}_{50}$ values were calculated (Table 4). 